\title{
The pyrrolo-1,5-benzoxazepine, $\mathrm{PBOX}-15$, enhances TRAIL-induced apoptosis by upregulation of DR5 and downregulation of core cell survival proteins in acute lymphoblastic leukaemia cells
}

\author{
SEEMA-MARIA NATHWANI ${ }^{1}$, LISA M. GREENE ${ }^{1}$, STEFANIA BUTINI ${ }^{2}$, GIUSEPPE CAMPIANI ${ }^{2}$, \\ D. CLIVE WILLIAMS ${ }^{1}$, AFSHIN SAMALI ${ }^{3}$, EVA SZEGEZDI ${ }^{3}$ and DANIELA M. ZISTERER ${ }^{1}$

\footnotetext{
${ }^{1}$ School of Biochemistry and Immunology, Trinity Biomedical Sciences Institute, Trinity College Dublin, Dublin 2, Ireland; ${ }^{2}$ European Research Centre for Drug Discovery and Development, University of Siena, Siena, Italy; ${ }^{3}$ Apoptosis Research Centre, Bioscience Research Building, National University of Ireland, Galway, Ireland
}

Received January 28, 2016; Accepted March 8, 2016

DOI: $10.3892 /$ ijo. 2016.3518

\begin{abstract}
Apoptotic defects are frequently associated with poor outcome in pediatric acute lymphoblastic leukaemia (ALL) hence there is an ongoing demand for novel strategies that counteract apoptotic resistance. The death ligand TRAIL
\end{abstract}

Correspondence to: Dr Seema M. Nathwani, School of Biochemistry and Immunology, Trinity Biomedical Sciences Institute, Trinity College Dublin, 152-160 Pearse Street, Dublin 2, Ireland

E-mail: nathwans@tcd.ie

Abbreviations: ALL, acute lymphoblastic leukaemia; Bcl-2, B-cell lymphoma 2; cFLIP, cellular FLICE (FADD-like IL-1 $\beta$-converting enzyme)-inhibitory protein; CI, combination index; CLL, chronic lymphocytic leukemia; CML, chronic myeloid leukemia; DISC, death inducing signaling complex; DMEM, Dulbecco's modified Eagle's medium; DR, death receptor; FBS, fetal bovine serum; GAPDH, glyceraldehyde 3-phosphate dehydrogenase; GSK-3 $\beta$, glycogen synthase kinase $3 \beta$; IAP, inhibitor of apoptosis protein; JC-1, 5,5',6,6'-tetrachloro-1,1',3,3'-tetraethylbenzimidazolyl-carbocyanine iodide; LY-294002, 2-(4-Morpholinyl)-8-phenyl-1(4H)-benzopyran4-one hydrochloride; Mcl-1, myeloid cell leukemia 1; MIM, mitochondrial inner membrane; MMP, mitochondrial membrane potential; MTAs, microtubular-targeting agents; mTOR, mammalian target of rapamycin; PARP, poly (ADP-ribose) polymerase; PBOX, pyrrolo-1,5-benzoxazepine; PBOX-15, 4-acetoxy-5-(1naphthyl)naphtho[2,3-b]pyrrolo[2,1-d][1,4]oxazepine; PBOX-6, 7-[(N,N-dimethylcarbamoyl)oxy]-6-(naphth-1-yl)pyrrolo[2,1-d] [1,5]benzoxazepine; PDK1, phosphoinositide-dependent protein kinase 1; PI, propidium iodide; PI3K, phosphoinositide-3-kinase; $\mathrm{PIP}_{3}$, phosphatidylinositol (3,4,5)-trisphosphate; PTEN, phosphatase and tensin homologue deleted on chromosome ten; RPMI, Roswell Park Memorial Institute; TNF, tumour necrosis factor; TRAIL, tumour necrosis factor-related apoptosis-inducing ligand; XIAP, $\mathrm{X}$-linked inhibitor of apoptosis protein

Key words: tumour necrosis factor-related apoptosis-inducing ligand, apoptosis, caspase, Akt, inhibitor of apoptosis protein, acute lymphoblastic leukaemia (tumour necrosis factor-related apoptosis-inducing ligand) and its selective tumour receptor system has attracted exceptional clinical interest. However, many malignancies including ALL are resistant to TRAIL monotherapy. Tumour resistance can be overcome by drug combination therapy. TRAIL and its agonist antibodies are currently undergoing phase II clinical trials with established chemotherapeutics. Herein, we present promising therapeutic benefits in combining TRAIL with the selective anti-leukaemic agents, the pyrrolo-1,5-benzoxazepines (PBOXs) for the treatment of ALL. PBOX-15 synergistically enhanced apoptosis induced by TRAIL and a DR5-selective TRAIL variant in ALL-derived cells. PBOX-15 enhanced TRAIL-induced apoptosis by dual activation of extrinsic and intrinsic apoptotic pathways. The specific caspase- 8 inhibitor, Z-IETD-FMK, identified the extrinsic pathway as the principal mode of apoptosis. We demonstrate that PBOX-15 can enhance TRAIL-induced apoptosis by upregulation of DR5, reduction of cellular mitochondrial potential, activation of the caspase cascade and downregulation of PI3K/Akt, c-FLIP, Mcl-1 and IAP survival pathways. Of note, the PI3K pathway inhibitor LY-294002 significantly enhanced the apoptotic potential of TRAIL and PBOX-15 validating the importance of Akt downregulation in the TRAIL/PBOX-15 synergistic combination. Considering the lack of cytotoxicity to normal cells and ability to downregulate several survival pathways, PBOX-15 may represent an effective agent for use in combination with TRAIL for the treatment of ALL.

\section{Introduction}

Acute lymphoblastic leukaemia (ALL) is a malignant clonal proliferation of lymphoid progenitor cells (1). There are two main immunological types of ALL; pre-B cell and pre-T cell. ALL is the most common type of childhood cancer (2). It represents $75 \%$ of childhood leukaemia whereas it is the least common type of adult leukaemia. The American Cancer Society estimates that 3,000 children and adolescents will be diagnosed with ALL this year (ACS website). Advances in the 
understanding of the molecular genetics and pathogenesis of the disease together with the development of novel treatment strategies have contributed to pediatric cure rates of up to $90 \%(1,3)$. However, some patients elude this due to presentation of poor prognostic factors and acquired drug resistance. Furthermore, the modern cure rates for adult ALL have yet to exceed $40 \%$ and lag far behind those observed in childhood ALL (1). In order to maintain current remission rates in children and to improve the moderate cure rates for adults there is a need to develop novel chemotherapeutic agents for the treatment of ALL.

Death receptors (DRs) are members of the tumour necrosis factor (TNF) receptor superfamily. These receptors are capable of activating the cells extrinsic apoptotic pathways in response to extracellular death signals (4). Eight human DRs have been identified to date (5). Two DRs (DR4 and DR5) are preferentially expressed on cancer cells $(6,7)$. Ligands targeting these death receptors and/or molecules that induce expression of these receptors can be exploited to selectively induce cell death in cancer cells whilst sparing normal healthy cells (6). The TNF family member, tumor necrosis factor-related apoptosis-inducing ligand (TRAIL), is a potent ligand for DR4 and DR5 (8). Non-functional decoy TRAIL receptors (DcR1 and DcR2) are expressed on normal cells protecting them from the TRAIL death signal. Hence, TRAIL can selectively induce apoptosis in a vast array of tumourderived cell lines and consequently inhibit tumour growth in various animal models (9). This discovery instigated the rapid development of therapeutic agents including recombinant human TRAIL and agonistic monoclonal antibodies against DR4 and DR5 $(10,11)$. However, despite the initial appeal of TRAIL as a selective anticancer agent many cancers including hematological malignancies are resistant to TRAIL monotherapy, thus, limiting its therapeutic potential (12). Conversely, TRAIL was shown to induce the survival and proliferation in a subset of TRAIL resistant ALL cells (13). Combination therapies offer a solution to overcoming resistance to TRAIL monotherapy $(14,15)$. Early clinical trials using monoclonal agonistic antibodies which target DR4 with established chemotherapeutics such as paclitaxel and carboplatin were well tolerated and demonstrated clinical benefit (16). Further studies are required to identify agents that sensitise tumour cells to TRAIL together with extensive biochemical studies to identify signalling pathways involved in synergistic combinations.

Our group recently demonstrated that pyrrolo-1,5-benzoxazepine-15 (PBOX-15) increased DR5 expression in multiple myeloma cells and sensitised these cells to TRAIL-induced cell death (17). The PBOXs are a novel group of tubulin targeting agents (18) which potently induce apoptosis in a wide spectrum of cancer cells including those originating from the four main types of leukaemia (19-22) and those exhibiting multi-drug resistance (23). The anti-leukaemic potential of the PBOXs extended to ex vivo CML and CLL patient samples including those derived from poor prognostic subgroups and those resistant to current first line therapies $(20,24)$. Furthermore, PBOX-6, a potent representative member of the PBOXs, significantly reduced the growth of CML cells in vivo whilst exhibiting no adverse effects (24). Moreover, the PBOXs are selective anticancer agents and display no toxicity towards

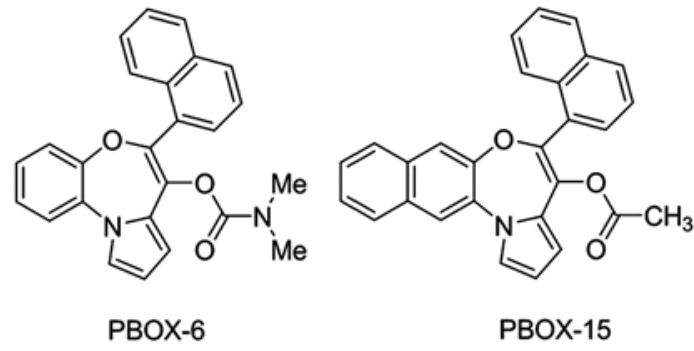

Figure 1. Chemical structure of pyrrolo-1,5-benzoxazepine compounds, PBOX-6 and PBOX-15.

normal peripheral blood cells or bone marrow cells at concentrations that are toxic to leukaemia cells $(20,21)$. Hence, the PBOXs represent an ideal chemotherapeutic to combine with TRAIL for the treatment of ALL. Herein, we present novel findings demonstrating the potential of the PBOXs as single agents and in combination with TRAIL for the treatment of ALL. Several key signalling pathways mediating synergistic combinations are identified.

\section{Materials and methods}

Unless otherwise stated, chemicals were obtained from SigmaAldrich (Poole, UK) and tissue culture vessels were sourced from Greiner Bio-One GmbH (Frickenhausen, Germany).

Cell culture. Acute lymphoblastic leukaemia cell lines, Jurkat (T cell), Nalm-6 and Reh (B cell precursor) were purchased from DSMZ (Braunschweig, Germany) and CEM ( T cell) were originally obtained from the American Type Culture Collection (ATCC; Manassas, VA, USA). All cells were maintained in Roswell Park Memorial Institute (RPMI)-1640 medium enhanced with GlutaMAX-I and supplemented with $10 \%$ fetal bovine serum (FBS), 50 units/ml penicillin and $50 \mu \mathrm{g} / \mathrm{ml}$ streptomycin (all from Gibco-Invitrogen, Carlsbad, CA, USA). Cells were maintained at densities between $0.5-1.5 \times 10^{6}$ cells $/ \mathrm{ml}$ (Jurkat), $0.2-2 \times 10^{6}$ cells $/ \mathrm{ml}$ (CEM) or $0.5-4 \times 10^{6}$ cells $/ \mathrm{ml}$ (Nalm-6 and Reh) in a humidified incubator at $37^{\circ} \mathrm{C}$ in $5 \% \mathrm{CO}_{2}$.

Reagents. The pyrrolo-1,5-benzoxazepine compounds, 7-[(N,N-dimethylcarbamoyl)oxy]-6-(naphth-1-yl)pyrrolo[2,1$d][1,5]$ benzoxazepine (PBOX-6) and 4-acetoxy-5-(1-naphthyl) naphtho[2,3-b]pyrrolo[2,1- $d][1,4]$ oxazepine (PBOX-15) were synthesised following the procedures described in the study by McGee et al (25). The compounds were dissolved in ethanol and stored at $-20^{\circ} \mathrm{C}$. Their chemical structure is shown in Fig. 1. Recombinant human TRAIL (amino acids 114-281) was purchased from Merck Millipore (Nottingham, UK) in a buffer containing $500 \mathrm{mM} \mathrm{NaCl}, 10 \mathrm{mM} \mathrm{Na} \mathrm{HPO}_{4}, 2.7 \mathrm{mM}$ $\mathrm{KCl}, 2 \mathrm{mM} \mathrm{KH}{ }_{2} \mathrm{PO}_{4}, 1 \mathrm{mM}$ DTT, $\leq 10 \%$ glycerol. The TRAIL was aliquoted as supplied $(1.2 \mathrm{mg} / \mathrm{ml})$ and stored at $-70^{\circ} \mathrm{C}$. A DR5-selective TRAIL variant, D269H/E195R, was generated as previously described (26,27). D269H/E195R was diluted to a concentration of $0.5 \mathrm{mg} / \mathrm{ml}$ in a buffer containing $200 \mathrm{mM}$ $\mathrm{NaPi}$ (pH 7.4), $150 \mathrm{mM} \mathrm{NaCl}, 10 \%$ glycerol, $1 \mathrm{M}$ DTT and $20 \mathrm{mM} \mathrm{ZnSO}_{4}$. Aliquots were then stored at $-70^{\circ} \mathrm{C}$. Monoclonal antibodies capable of neutralising DR5 were purchased from 
Alexis (Enzo Life Sciences, Exeter, UK). Caspase inhibitors, z-IETD-fmk (caspase-8), z-LEHD-fmk (caspase-9) and z-VAD-fmk (general caspase inhibitor), all purchased from Merck Biosciences Ltd. (Nottingham, UK), were dissolved in DMSO and aliquoted prior to storage at $-20^{\circ} \mathrm{C}$. The phosphoinositide 3-kinase (PI3K) inhibitor, LY294002, was also dissolved in DMSO and stored at $-20^{\circ} \mathrm{C}$.

Cell proliferation. Cell proliferation was monitored using AlamarBlue $^{\mathrm{TM}}$ dye (BioSource, Invitrogen, Carlsbad, CA, USA) which changes to a fluorescent state in the reduced environment of living cells. ALL cells were seeded onto 96-well plates and then treated with a range of concentrations of PBOX-6 or PBOX-15 for $72 \mathrm{~h}$. AlamarBlue ${ }^{\mathrm{TM}}$ [final concentration $10 \%(\mathrm{v} / \mathrm{v})]$ was added and incubated at $37^{\circ} \mathrm{C}$. Fluorescence was measured at an excitation wavelength of $544 \mathrm{~nm}$ and an emission wavelength of $590 \mathrm{~nm}$ using a SpectraMax Gemini spectrofluorometric plate reader (Molecular Devices, Sunnyvale, CA, USA). The results were expressed as the percentage cell viability relative to vehicle-treated control cells $(100 \%)$. Dose-response curves were plotted and $\mathrm{IC}_{50}$ values (concentration of drug resulting in 50\% reduction in cell viability) were obtained using Prism GraphPad 4.

Determination of DNA content. Following treatment, cells were harvested by centrifugation at $800 \mathrm{x}$ g for $10 \mathrm{~min}$. Cell pellets were resuspended in $200 \mathrm{ml}$ PBS and fixed by a dropwise addition of $2 \mathrm{ml}$ of ice-cold $70 \%$ (v/v) ethanol/PBS while gently vortexing. Following overnight fixation at $-20^{\circ} \mathrm{C}$ the cells were again centrifuged to remove the ethanol and resuspended in PBS supplemented with $0.5 \mathrm{mg} / \mathrm{ml}$ RNase A and $0.15 \mathrm{mg} / \mathrm{ml}$ propidium iodide (PI). Cells were incubated in the dark at $37^{\circ} \mathrm{C}$ for $30 \mathrm{~min}$. Fluorescence from PI was measured on a linear scale using a FACSCalibur flow cytometer (BectonDickinson, San Jose, CA, USA). Data collections $(10,000$ events per sample) were gated to exclude cell debris and cell aggregates. Fluorescence (from PI) was proportional to the amount of DNA present in each entity and therefore indicated the stage of the cell cycle. Cells in $\mathrm{G}_{0} / \mathrm{G}_{1}$ were diploid (2N DNA content), cells in the $\mathrm{S}$ phase had DNA contents between $2 \mathrm{~N}$ and $4 \mathrm{~N}$, cells in $\mathrm{G}_{2} / \mathrm{M}$ were tetraploid (4N DNA content), while apoptotic cells were hypoploid and contained $<2 \mathrm{~N}$ DNA. All data was recorded and analysed using the CellQuest software (Becton-Dickinson).

Analysis of protein expression, phosphorylation and cleavage by western blotting. Cells were harvested in a RIPA buffer consisting of $50 \mathrm{mM}$ Tris- $\mathrm{HCl}(\mathrm{pH} 8.0), 150 \mathrm{mM}$ sodium chloride, $1.0 \%(\mathrm{v} / \mathrm{v})$ Igepal CA-630 (NP-40), 0.5\% (w/v) sodium deoxycholate, and $0.1 \%(\mathrm{w} / \mathrm{v})$ sodium dodecyl sulphate (SDS) supplemented with protease and phosphatase inhibitor cocktails from Sigma-Aldrich. The samples were then diluted in 3X sample buffer [187.5 mM Tris-HCl (pH 6.8), 6\% (w/v) SDS, 30\% glycerol, $150 \mathrm{mM}$ DTT, $0.03 \% \mathrm{w} / \mathrm{v}$ bromophenol blue]. For the detection of PARP, cells were harvested in whole cell lysis buffer containing $62.5 \mathrm{mM}$ Tris (pH 6.8), $2 \%$ (w/v) SDS, $10 \%$ (v/v) glycerol, $0.00125 \%$ (w/v) bromophenol blue and $50 \mathrm{mM}$ DTT and the samples sonicated briefly. All extracts were denatured at $65^{\circ} \mathrm{C}$ for $10 \mathrm{~min}$ before separation of proteins on a polyacrylamide gel and transfer to PVDF membrane. The PVDF transfers were probed overnight at $4^{\circ} \mathrm{C}$ with primary antibodies and then incubated with horseradish peroxidase-conjugated anti-mouse or anti rabbit secondary antibodies (Promega, Madison, WI, USA). Protein expression was visualised by enhanced chemiluminescence. All primary antibodies were supplied by Cell Signaling Technology Inc. (Beverly, MA, USA) except for those generated against PARP, Bcl-2, pro-caspase-3, c-FLIP, $\beta$-tubulin and GAPDH which were obtained from Merck Biosciences and Bcl-x, and BubR1 from BD Biosciences (Bedford, MA, USA).

Measurement of mitochondrial membrane potential. Mitochondrial transmembrane potential was measured as a function of drug treatment using the potentiometric dye 5,5',6,6'-tetrachloro-1,1',3,3'-tetraethylbenzimidazolylcarbocyanine iodide (JC-1) (Molecular Probes, Invitrogen, Germany). Following treatment, the cells were washed with PBS and stained with JC-1 $(5 \mu \mathrm{M})$ in PBS for $30 \mathrm{~min}$ at $37^{\circ} \mathrm{C}$. Cells were washed with PBS, resuspended in ice-cooled PBS and immediately assessed for red and green fluorescence by flow cytometry (FACSCalibur flow cytometer; BectonDickinson). Excitation at $488 \mathrm{~nm}$ and emission filters of 535 and $595 \mathrm{~nm}$ were used to quantify the population of mitochondria with green (JC-1 monomers) and red (JC-1 aggregates) fluorescence, respectively. The red-to-green fluorescence ratio for individual cells was calculated using the CellQuest software (Becton-Dickinson).

Analysis of TRAIL receptor expression. Cells were washed twice in $1 \%(\mathrm{w} / \mathrm{v}) \mathrm{BSA} / \mathrm{PBS}$ then incubated for $45 \mathrm{~min}$ on ice with monoclonal antibodies to DR4, DR5, DcR1, DcR2 or isotype control antibodies (Enzo Life Sciences) in BSA/PBS. The cells were again washed twice in BSA/PBS then incubated in darkness for a further $45 \mathrm{~min}$ in anti-mouse IgG-FITC (DakoCytomation, Glostrup, Denmark) in BSA/PBS. Cells were washed, resuspended in PBS and TRAIL receptor expression detected by flow cytometry (FACSCalibur; BectonDickinson). Results were then analysed using the FlowJo software (Tree Star Inc., San Carlos, CA, USA).

Statistical analysis. Results were presented as mean \pm SEM. The statistical analysis of experimental data was performed using the computer program Prism GraphPad 4. P-values were determined using either a two-tailed Student's paired $t$-test or one-way ANOVA (Bonferroni's test). A value of $\mathrm{P}<0.05$ was considered to be significant.

Analysis of drug interactions. Drug interactions were determined by median dose effect analysis using the Calcusyn software (Biosoft, Cambridge, UK). This method is based on the drug effect equation of Chou and Talalay and can determine the degree of synergism or antagonism between two compounds by generating a combination index $(\mathrm{CI})$ value. $\mathrm{CI}$ values of $<1,=1$ and $>1$ indicate synergism, an additive effect and antagonism, respectively.

\section{Results}

Effect of PBOX compounds on viability of ALL cells. Jurkat, CEM, Nalm-6 and Reh cells were treated for $72 \mathrm{~h}$ with a range 
A Jurkat

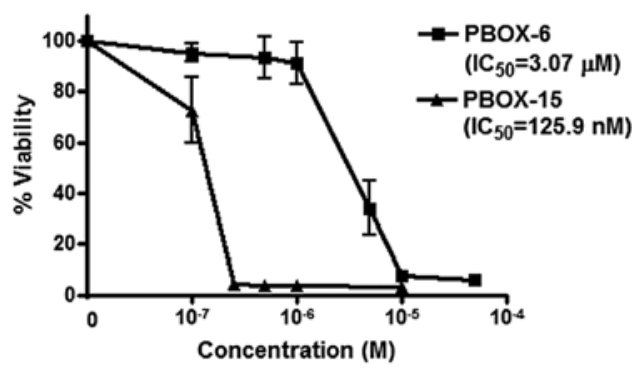

C Nalm-6

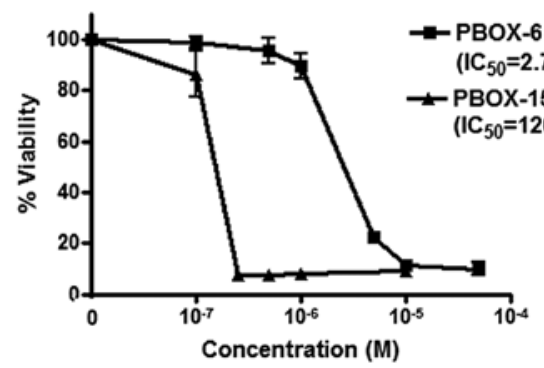

B CEM

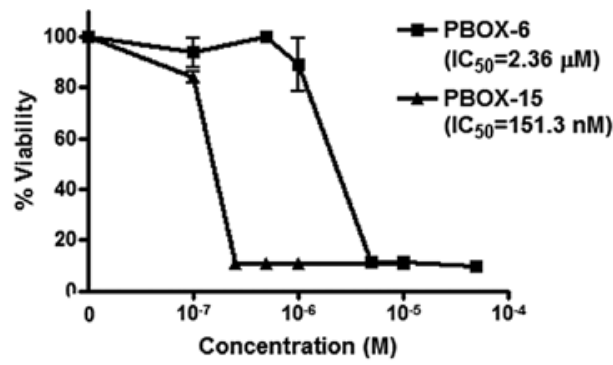

D Reh

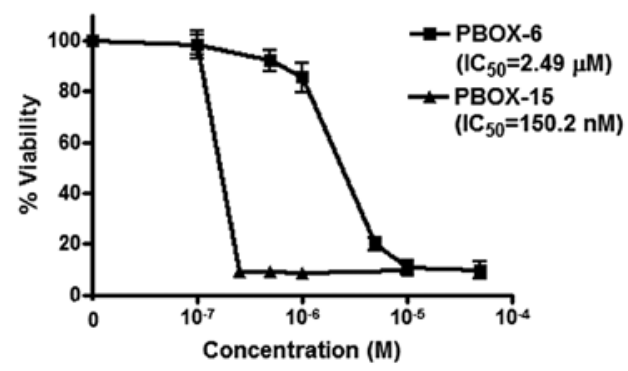

Figure 2. PBOX compounds, PBOX-6 and PBOX-15, reduce viability of ALL cells. (A) Jurkat, (B) CEM, (C) Nalm-6 and (D) Reh ALL cells were seeded onto 96-well plates $(200,000-500,000$ cells $/ \mathrm{ml})$ and were treated in triplicate with vehicle alone [1\% (v/v) ethanol] or a range of concentrations of PBOX-6 or PBOX-15 for $72 \mathrm{~h}$. Cell viability was detected by AlamarBlue ${ }^{\mathrm{TM}}$ assay and results were expressed as the percentage cell viability relative to vehicle-treated control cells $(100 \%)$. Values represent the mean \pm the SEM for three separate experiments. $\mathrm{IC}_{50}$ values (concentration of compound resulting in $50 \%$ reduction in cell viability) were obtained using Prism GraphPad 4 software.
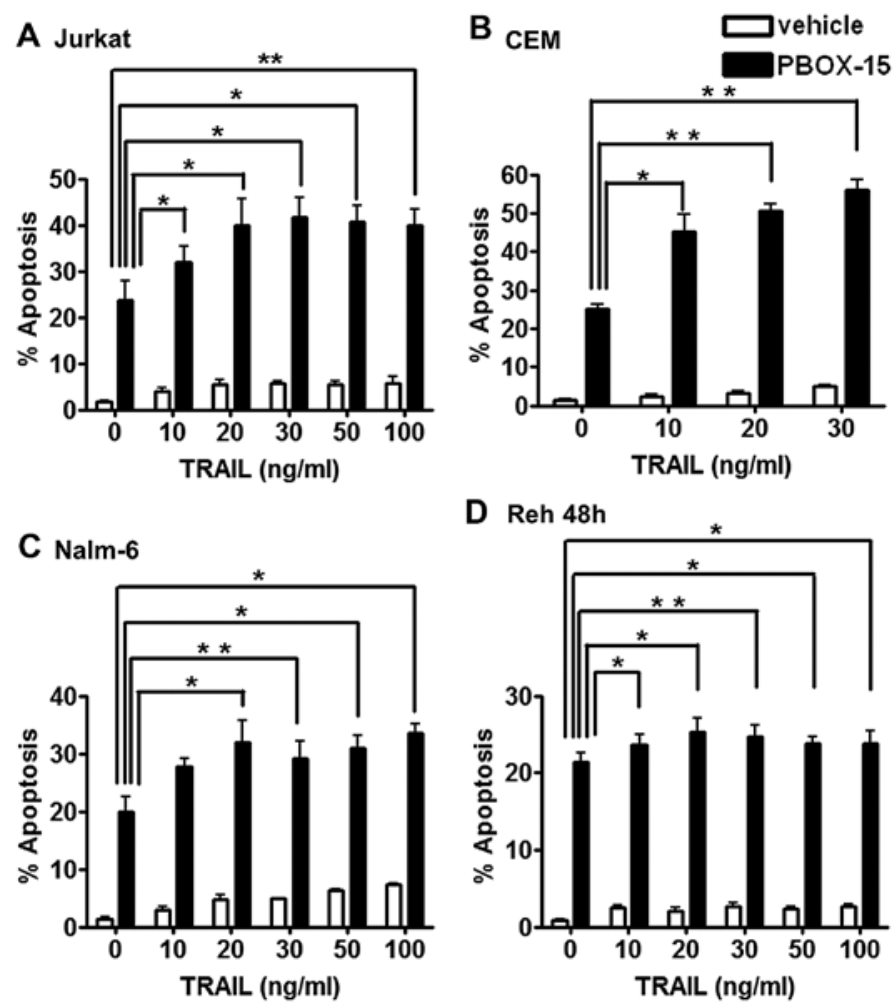

Figure 3. The PBOX-15/TRAIL combination significantly enhances apoptosis in ALL cells compared to either agent alone. ALL cells were treated for $24 \mathrm{~h}$ [Jurkat (A), CEM (B) and Nalm-6 (C)] or $48 \mathrm{~h}$ [Reh (D)] with vehicle [0.2\% (v/v) ethanol] or PBOX-15 (1 $\mu$ M) in the presence or absence of TRAIL $(10-100 \mathrm{ng} / \mathrm{ml})$. The cells were then fixed in ethanol, stained with propidium iodide and DNA content assessed by flow cytometry using CellQuest. Cells in the subG $\mathrm{G}_{0} / \mathrm{G}_{1}$ phase $(<2 \mathrm{~N}$ DNA) were deemed apoptotic. Values represent the mean \pm SEM for three independent experiments. A P-value $<0.05$ was considered to be statistically significant $\left({ }^{*} \mathrm{P}<0.05,{ }^{* *} \mathrm{P}<0.01\right)$.

of concentrations of PBOX-6 and PBOX-15. Cell viabilities were measured by AlamarBlue assay (Fig. 2). PBOX-6 and
PBOX-15 reduced viability of both T cell ALL cells (Jurkat and CEM) and B cell precursor ALL cells (Nalm-6 and Reh) 
Table I. TRAIL synergistically enhances PBOX-15-induced apoptosis in ALL cells.

\begin{tabular}{|c|c|c|c|c|c|c|}
\hline & TRAIL (ng/ml) & PBOX-15 $(\mu \mathrm{M})$ & Fraction affected & $\mathrm{CI}$ & Symbol & Description \\
\hline \multirow[t]{5}{*}{ Jurkat } & 10 & 1 & 0.3197 & 0.629 & +++ & Synergism \\
\hline & 20 & 1 & 0.4001 & 0.377 & +++ & Synergism \\
\hline & 30 & 1 & 0.4163 & 0.341 & +++ & Synergism \\
\hline & 50 & 1 & 0.4063 & 0.363 & +++ & Synergism \\
\hline & 100 & 1 & 0.3985 & 0.38 & +++ & Synergism \\
\hline \multirow[t]{3}{*}{ CEM } & 10 & 1 & 0.4501 & 0.483 & +++ & Synergism \\
\hline & 20 & 1 & 0.5043 & 0.448 & +++ & Synergism \\
\hline & 30 & 1 & 0.5604 & 0.413 & +++ & Synergism \\
\hline \multirow[t]{5}{*}{ Nalm-6 } & 10 & 1 & 0.2717 & 0.743 & ++ & Moderate synergism \\
\hline & 20 & 1 & 0.3185 & 0.502 & +++ & Synergism \\
\hline & 30 & 1 & 0.2917 & 0.63 & +++ & Synergism \\
\hline & 50 & 1 & 0.3083 & 0.553 & +++ & Synergism \\
\hline & 100 & 1 & 0.335 & 0.455 & +++ & Synergism \\
\hline \multirow[t]{5}{*}{ Reh } & 10 & 1 & 0.237 & 1.083 & \pm & Nearly additive \\
\hline & 20 & 1 & 0.2537 & 0.986 & \pm & Additive \\
\hline & 30 & 1 & 0.2468 & 1.024 & \pm & Nearly additive \\
\hline & 50 & 1 & 0.2385 & 1.073 & \pm & Nearly additive \\
\hline & 100 & 1 & 0.2375 & 1.079 & \pm & Nearly additive \\
\hline
\end{tabular}

ALL cells were treated for $24 \mathrm{~h}$ (Jurkat, CEM and Nalm-6) or $48 \mathrm{~h}$ (Reh) with vehicle $(0.2 \%$ (v/v) ethanol) or PBOX-15 (1 $\mu \mathrm{M})$ and the indicated concentrations of TRAIL. The cells were then fixed in ethanol, stained with propidium iodide and DNA content assessed by flow cytometry using CellQuest. Cells in the subG $\mathrm{G}_{0} / \mathrm{G}_{1}$ phase $(<2 \mathrm{~N}$ DNA) were deemed apoptotic. Median dose effect analysis was carried out using the software program CalcuSyn. Combination index (CI) values for PBOX-15 in combination with TRAIL were generated. A CI value of less than one represents synergism while a CI value greater than one represents antagonism. A CI value equal to 1 indicates an additive effect.

in a dose-dependent manner. $\mathrm{IC}_{50}$ values (concentration of drug resulting in 50\% reduction in cell viability) for PBOX-6 were 3.1, 2.4, 2.8 and $2.5 \mu \mathrm{M}$ in Jurkat, CEM, Nalm-6 and Reh cells, respectively. Similarly, $\mathrm{IC}_{50}$ values for PBOX-15 were $0.13,0.15,0.13$ and $0.15 \mu \mathrm{M}$ in Jurkat, CEM, Nalm-6 and Reh cells, respectively. As PBOX-15 was found to be the more potent compound, it was chosen for further evaluation in combination with TRAIL.

Effect of PBOX-15 alone and in combination with TRAIL on cell cycle arrest and apoptosis in ALL cells. To investigate if PBOX-15 enhanced the apoptotic efficacy of TRAIL in ALL cells, we treated Jurkat, CEM, Nalm- 6 and Reh cells with either vehicle $(0.2 \% \mathrm{EtOH})$ or PBOX-15 $(1 \mu \mathrm{M})$ alone or in combination with either TRAIL (10-100 ng/ml) or TRAIL buffer (control, $0 \mathrm{ng} / \mathrm{ml}$ ) for $24 \mathrm{~h}$ (or $48 \mathrm{~h}$ for Reh cells). Apoptosis was quantified by flow cytometric analysis as the number of cells with hypoploid DNA content ( $<2 \mathrm{~N}$ DNA) (Fig. 3). In all four cell lines, treatment with TRAIL alone, even at the highest concentrations tested, resulted in low levels of apoptosis $<7 \%$ compared to $\sim 2 \%$ with buffer and vehicle alone. PBOX-15 alone resulted in between $20-25 \%$ apoptosis depending on the cell type. The combination of TRAIL and PBOX-15 resulted in statistically significant increases in apoptosis compared to PBOX alone or TRAIL alone in all four cell lines.
To determine if the enhancement in apoptosis we observed between TRAIL and PBOX-15 could be considered synergistic, we used the CalcuSyn program to perform a median dose analysis of our flow cytometry results (Table I). We found that PBOX-15 in combination with the indicated concentrations of TRAIL (10-100 ng/ml) was considered synergistic in Jurkat, CEM and Nalm-6 cells as they displayed combination index (CI) values of $<1$. The combination was found to be additive in Reh cells as the CI value was approximately equal to 1 in these cells (Table I).

We next examined the relationship between apoptosis and $\mathrm{G}_{2} \mathrm{M}$ arrest induced by PBOX-15 alone, TRAIL alone or the PBOX-15/TRAIL combination in ALL cells between 24-72 $\mathrm{h}$ (Fig. 4A-C). In all three cell lines, TRAIL induced only low levels of apoptosis even after $72 \mathrm{~h}$ in Jurkat (7.5 $\pm 0.2 \%)$, Nalm-6 $(2.4 \pm 0.2 \%)$ and Reh $(3.1 \pm 0.6 \%)$ compared to vehicle-treated cells which displayed $1.8 \pm 0.2,0.7 \pm 0.1$ and $1.7 \pm 0.4 \%$ apoptosis, respectively. This suggested that ALL cells exhibit only limited responsiveness to TRAIL alone. As expected, TRAIL alone did not significantly alter the percentage of cells undergoing $\mathrm{G}_{2} / \mathrm{M}$ arrest compared to vehicle-treated cells. The percentage of cells undergoing PBOX-15-induced apoptosis increased in a time-dependent manner, $19.8 \pm 3.1$ to $78.1 \pm 0.9 \%$ in Jurkats (Fig. 4A), $22.8 \pm 4.6$ to $57.0 \pm 3.6 \%$ in Nalm-6 (Fig. 4B) and $3.8 \pm 1.0$ to $42.0 \pm 2.6 \%$ in Reh (Fig. $4 \mathrm{C}$ ) from 24 to $72 \mathrm{~h}$. Levels of $\mathrm{G}_{2} / \mathrm{M}$ decreased over time from $47.4 \pm 3.4$ to $9.1 \pm 2.9 \%$ in 

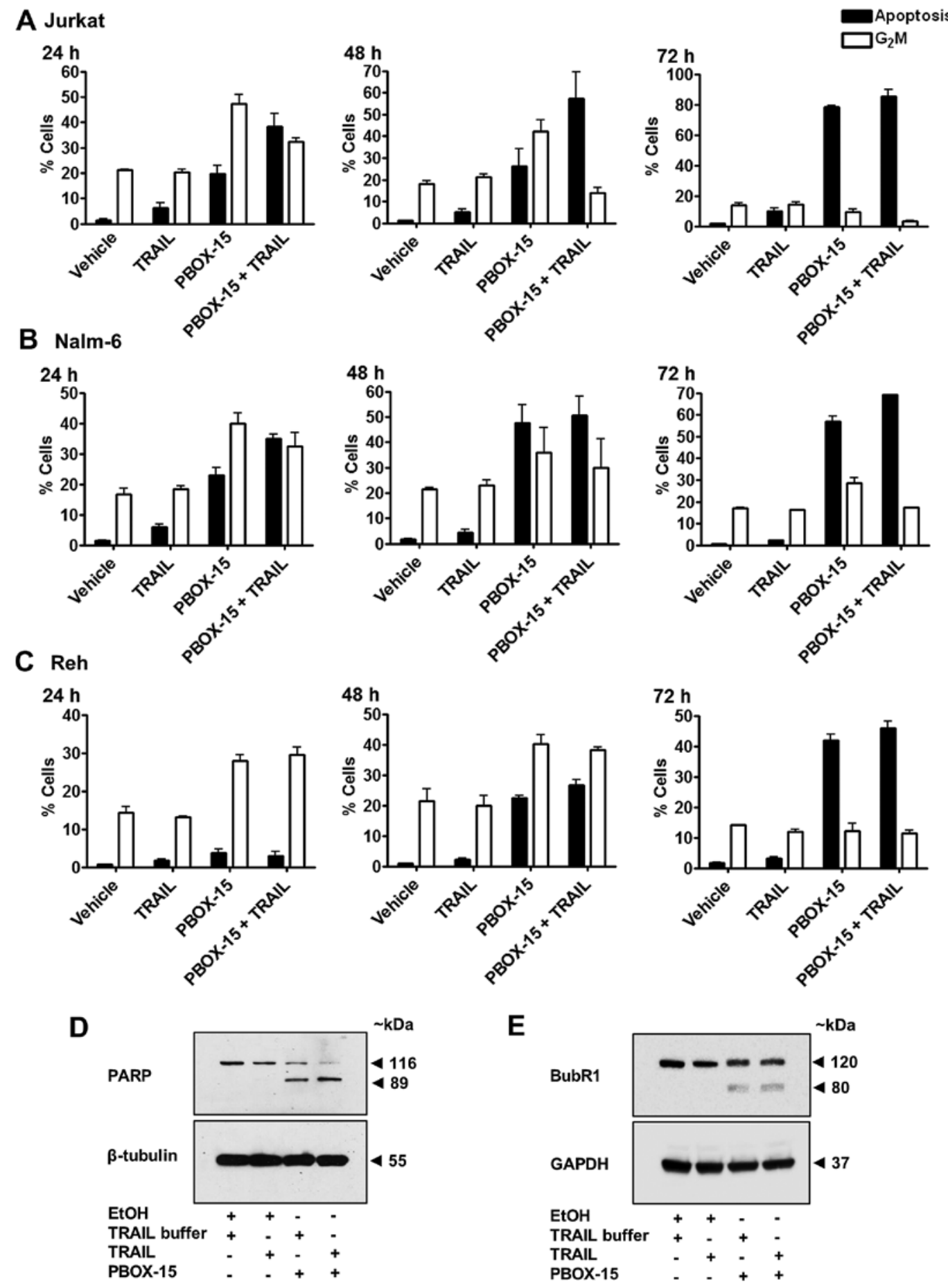

Figure 4. The enhancement of apoptosis induced by PBOX-15/TRAIL is associated with a reduction in $\mathrm{G}_{2} / \mathrm{M}$ arrest compared to PBOX-15 alone. (A) Jurkat, (B) Nalm- 6 and $(C)$ Reh cells $(500,000$ cells $/ \mathrm{ml})$ were treated with vehicle $[0.2 \%(\mathrm{v} / \mathrm{v})$ ethanol] or PBOX-15 $(1 \mu \mathrm{M}) \pm \mathrm{TRAIL}(20 \mathrm{ng} / \mathrm{ml})$ for 24,48 or $72 \mathrm{~h}$. The cells were fixed in ethanol, stained with propidium iodide and their DNA content assessed by flow cytometry. Analysis of data was performed using the CellQuest software. Fluorescence was proportional to the amount of DNA present in each entity and therefore indicated the stage of the cell cycle. $\mathrm{Cells}_{\mathrm{s}}$ in the subG $\mathrm{G}_{0} / \mathrm{G}_{1}$

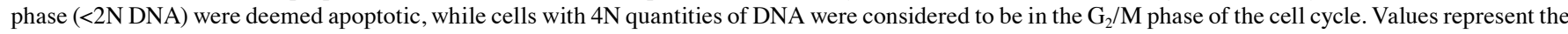
mean \pm SEM for three independent experiments. (D and E) Jurkat cells $(500,000$ cells $/ \mathrm{ml})$ were treated with vehicle $[0.2 \%(\mathrm{v} / \mathrm{v})$ ethanol] or PBOX-15 $(1 \mu \mathrm{M}) \pm$ TRAIL ( $20 \mathrm{ng} / \mathrm{ml}$ ) for $24 \mathrm{~h}$. Expression of PARP and BubR1 was assessed by western blot analysis. Expression of $\beta$-tubulin and GAPDH were used as loading controls. Blots are representative of three independent experiments.

Jurkats and $39.9 \pm 3.5$ to $28.5 \pm 2.6 \%$ in Nalm- 6 from 24 to $72 \mathrm{~h}$. Reh cells initially underwent an increase in $\mathrm{G}_{2} \mathrm{M}$ arrest from $27.0 \pm 1.6$ at $24 \mathrm{~h}$ to $40.2 \pm 2.9 \%$ at $48 \mathrm{~h}$ followed by a decrease to $12.3 \pm 2.3 \% \mathrm{G}_{2} \mathrm{M}$ at the later time-point of $72 \mathrm{~h}$, illustrating a slower time course of PBOX-15-induced response in Reh cells. These results illustrate that ALL cells undergo $\mathrm{G}_{2} \mathrm{M}$ arrest followed subsequently by apoptosis in response to PBOX-15 treatment.

ALL cells treated with the combination followed a similar pattern of time-dependent increases in apoptosis along with decreases in $\mathrm{G}_{2} \mathrm{M}$ as PBOX-15 alone, however, at any particular time-point, levels of apoptosis were higher and $\mathrm{G}_{2} \mathrm{M}$ lower 
than with PBOX-15 alone. For example, after $24 \mathrm{~h}$, percentage apoptosis was $19.8 \pm 3.1 \%$ and $\mathrm{G}_{2} \mathrm{M}$ arrest was $47.4 \pm 3.4 \%$ in Jurkats treated with PBOX-15 alone but with the TRAIL/ PBOX-15 combination apoptosis increased to $38.1 \pm 5.0 \%$ and $\mathrm{G}_{2} \mathrm{M}$ decreased to $32.2 \pm 1.5 \%$. Similarly, in Nalm-6 after $24 \mathrm{~h}$ PBOX-15/TRAIL induced $34.9 \pm 1.6 \%$ apoptosis and $32.5 \pm 4.4 \%$ $\mathrm{G}_{2} \mathrm{M}$ compared to $22.8 \pm 4.6 \%$ apoptosis and $39.9 \pm 3.5 \% \mathrm{G}_{2} \mathrm{M}$ with PBOX alone. In Reh cells, apoptosis rose from $22.5 \pm 1.2$ to $26.8 \pm 1.6 \%$ and $\mathrm{G}_{2} \mathrm{M}$ decreased from $40.2 \pm 2.9$ to $38.2 \pm 1.0 \%$, after treatment with combination for $48 \mathrm{~h}$ compared to PBOX alone. Therefore, the enhancement of apoptosis induced by the PBOX-15/TRAIL combination compared to either agent alone appears to be associated with acceleration in the transition from $\mathrm{G}_{2} \mathrm{M}$ arrest to subsequent apoptosis.

To support these findings, we also assessed cleavage of the DNA repair enzyme PARP and degradation of the mitotic spindle checkpoint protein BubR1. Cleavage of PARP is one of the key indicators of apoptosis. Treatment of Jurkat cells for $24 \mathrm{~h}$ with PBOX-15 alone or in combination with TRAIL resulted in cleavage of PARP, evidenced as a decrease in full-length PARP (116 kDa) and the appearance of a cleaved fragment (89 kDa) (Fig. 4D). In keeping with our flow cytometric data, the combination resulted in visibly higher amounts of PARP cleavage compared to the PBOX-15 alone. Although there was a slight reduction in the expression of full length PARP with TRAIL alone compared to vehicle treated cells, it was not sufficient to detect the cleaved fragment. We have previously demonstrated that the mitotic spindle checkpoint protein BubR1 is phosphorylated during $\mathrm{G}_{2} / \mathrm{M}$ arrest followed subsequently by degradation as arrest progressed to apoptosis following treatment of CML and prostate cancer cells with PBOX-15 $(28,29)$. We now demonstrate evidence of degradation of BubR1 indicative of apoptotic progression in Jurkat ALL cells treated for $24 \mathrm{~h}$ with PBOX-15 or PBOX-15 in combination with TRAIL (Fig. 4E). The appearance of a cleaved fragment at $\sim 80 \mathrm{kDa}$ suggests cleavage of BubR1 by caspases.

Role of DR5 in PBOX-15/TRAIL-induced apoptosis in ALL cells. We first sought to confirm death receptor expression patterns in Jurkat (Fig. 5A and B) and Nalm-6 (Fig. 5C and D) cells as representative $\mathrm{T}$ cell or B cell precursor ALL lines, respectively. Cell surface receptor expression was analysed by immunostaining using flow cytometry. We established that Jurkat cells predominantly express DR5 (Fig. 5A) identified as a shift to the right of the FL1-H peak compared to cells stained with the mouse isotype control antibody (negative control). Cell surface expression of DR4 (Fig. 5A) and DcR2 (Fig. 5B) was also observed in Jurkats but at lower levels than DR5. Expression of DR4 on Jurkat cells is somewhat controversial as conflicting reports documenting the DR4 status of Jurkats exist (30). Expression of DR4 may depend on the strain, the age or the culture conditions of the Jurkats. Receptor and decoy receptor expression on Nalm-6 cells (Fig. 5C and D) followed a similar pattern to Jurkats. Expression of DR5 was not as pronounced on Nalm-6 as on Jurkat cells.

It has been previously shown that other microtubuletargeting agents, such as paclitaxel, can increase cell surface expression of DR5 $(31,32)$. We next sought to delineate if PBOX-15 enhanced TRAIL-induced apoptosis by affecting the expression of DR5. We determined by flow cytometric immunostaining that PBOX-15 increased the cell surface expression of DR5 on Jurkat cells, evidenced by a shift to the right in the FL1-H peak compared to EtOH-treated cells (Fig. 5E). This finding was supported by western blots displaying upregulation in whole cell expression of DR5 after treatment with PBOX-15 alone or in combination with TRAIL compared to vehicle controls (Fig. 5F).

To establish the importance of DR5 in PBOX-15/TRAILinduced apoptosis, we treated Jurkat cells with PBOX alone or in combination with TRAIL or a TRAIL variant selective for DR5 (D269H/E196R). We found that the DR5-selective TRAIL variant enhanced PBOX-induced apoptosis with a similar efficacy as wild-type TRAIL (Fig. 5G). To further delineate the role of DR5 in PBOX-15/TRAIL induced apoptosis, Jurkat cells were pre-treated with a DR5 neutralising antibody for $1 \mathrm{~h}$ prior to treatment with PBOX-15 and/or TRAIL. The presence of the DR5 neutralising antibody abrogated the enhancement of apoptosis usually evident with the PBOX-15 in combination with either wild-type TRAIL or the DR5-specific TRAIL to the same levels as PBOX-15 alone (Fig. 5H). This result indicated the importance of DR5 in PBOX-15 and TRAIL cooperation.

Involvement of caspases in PBOX/TRAIL-induced apoptosis in ALL cells. To elucidate the apoptotic pathways recruited by PBOX-15 and TRAIL, alone and in combination, we next investigated the involvement of upstream initiator caspases, caspase- 8 and -9 . We established that treatment of Jurkat cells with the TRAIL/PBOX-15 combination resulted in processing of both pro-caspase- 8 and pro-caspase- 9 indicative of the involvement of the extrinsic and intrinsic apoptotic pathways, respectively. Processing was evidenced by western blot analysis as the disappearance of bands corresponding to the size of the pro-form of the caspases and in the case of caspase- 8 , the appearance of cleaved active fragments (Fig. 6A). Processing of a downstream effector caspase, pro-caspase-3, was also evident in Jurkat cells treated with PBOX-15 alone or in combination with TRAIL (Fig. 6A).

Caspase activity is modulated by the presence of endogenous caspase inhibitors such as cellular FLICE-inhibitory protein (c-FLIP) (33) or inhibitor of apoptosis proteins (IAPs) (34). Overexpression of c-FLIP may contribute to resistance to TRAIL through inhibition of the signalling cascade initiated by DR5 (12). Treatment of Jurkat cells with PBOX-15 in combination with TRAIL resulted in downregulation of c-FLIP protein expression (Fig. 6B). A high level of IAP expression in cancer cells also represents an important anti-apoptotic mechanism and is associated with chemoresistance. PBOX-15 alone was found to reduce the expression of cIAP-2 and XIAP and to a lesser extent cIAP-1 and livin compared to vehicle treated cells (Fig. 6C). A combination of PBOX-15 and TRAIL led to a greater reduction in expression of XIAP compared to PBOX-15 alone. It should be noted that endogenous levels of livin in Jurkat cells tends to be low. These results are of interest as it has been previously shown that XIAP inhibitors cooperate with TRAIL to induce apoptosis in ALL cells (14).

To further investigate the role of initiator caspases in PBOX/TRAIL induced apoptosis we pre-treated Jurkat and Nalm-6 cells with irreversible cell permeable inhibitors of 
A
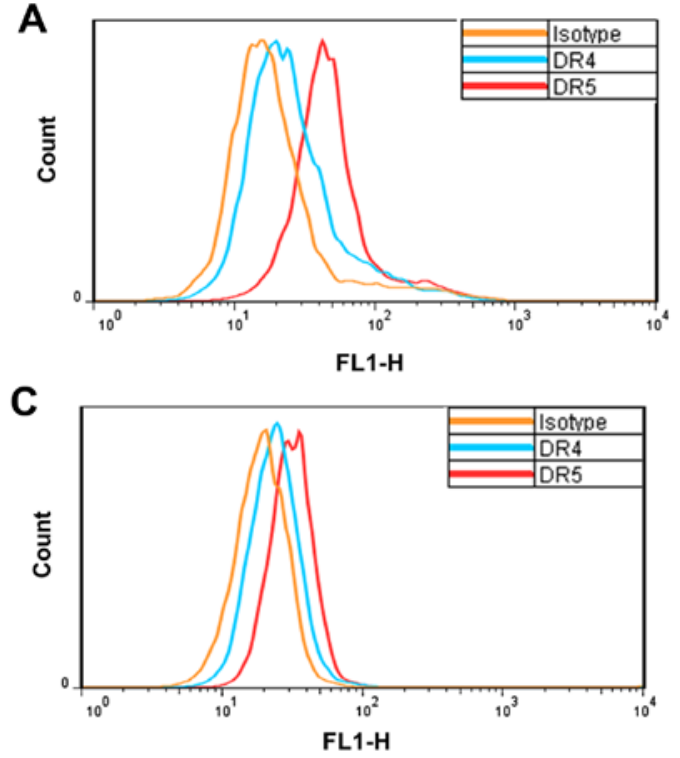

E

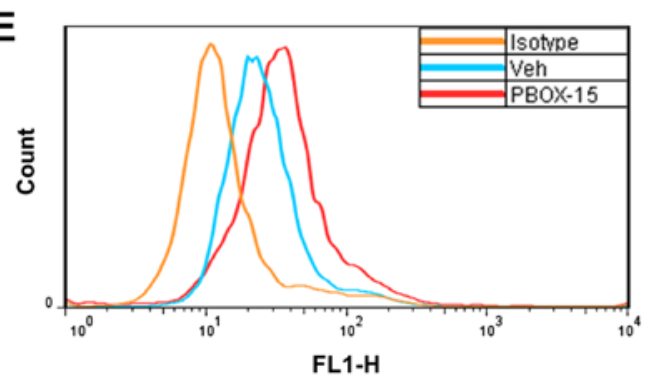

G

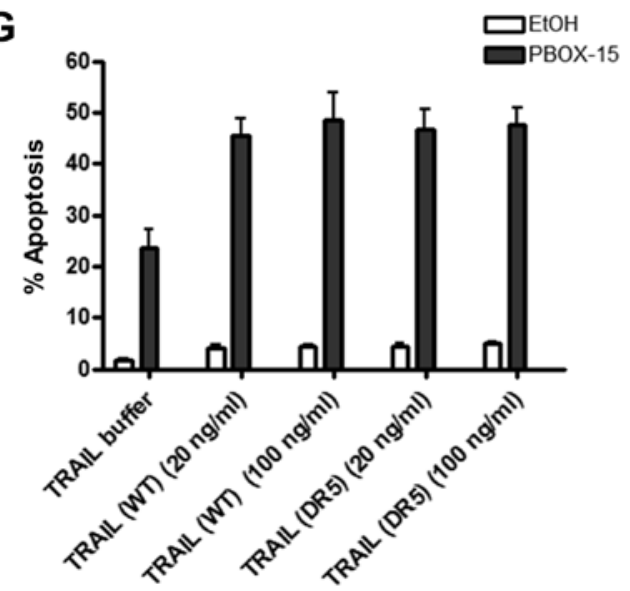

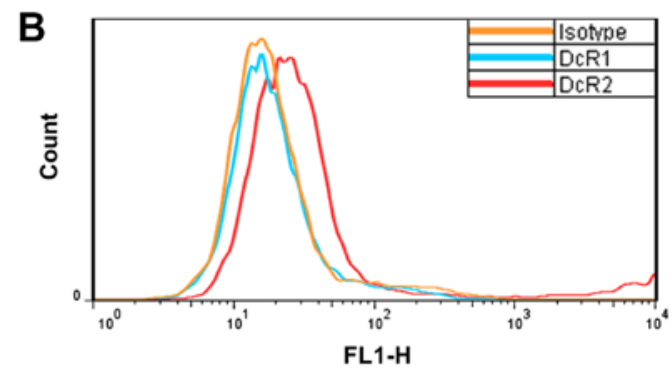

D

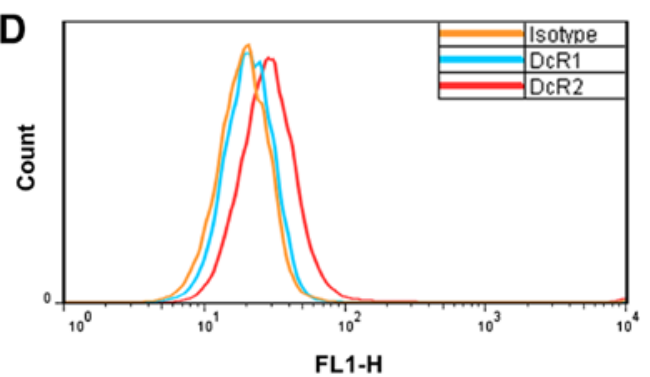

$\mathbf{F}$

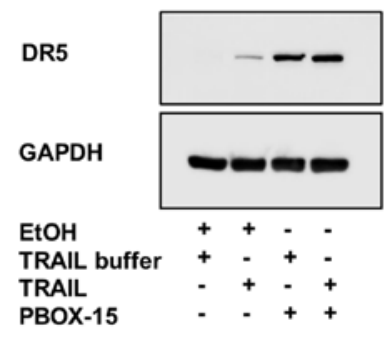

H

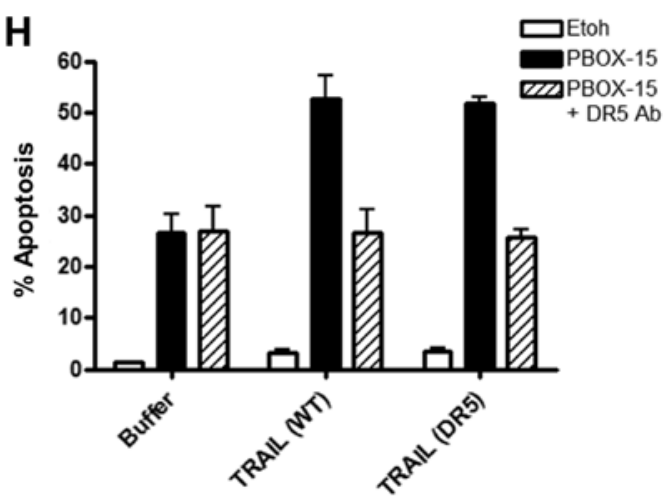

Figure 5. PBOX-15 upregulates cell surface and whole cell expression of DR5 in Jurkat ALL cells. (A and B) Jurkat or (C and D) Nalm-6 cells (200,000 cell/ml) were probed with monoclonal antibodies generated against receptors DR4 or DR5 (A and C) and decoy receptors DcR1 or DcR2 (B and D) followed by anti-mouse IgG FITC-conjugated secondary antibodies. Mouse isotype IgG1 control antibodies were used as a negative control. Cell surface expression of the receptors was then detected by flow cytometry. (E) Jurkat cells $(500,000$ cells $/ \mathrm{ml})$ were treated with vehicle [0.2\% (v/v) ethanol] or PBOX-15 (1 $\mu \mathrm{M})$ for $20 \mathrm{~h}$. To assess the effect of PBOX-15 on cell surface expression of DR5, the cells $(200,000$ cell/ml) were probed with monoclonal antibodies generated against DR5 as described above. (F) Jurkat cells $(500,000$ cells $/ \mathrm{ml})$ were treated with vehicle $[0.2 \%$ (v/v) ethanol] or PBOX-15 (1 $\mu \mathrm{M}) \pm$ TRAIL (20 ng/ml) for $24 \mathrm{~h}$. Expression of DR5 and GAPDH (loading control) was assessed by western blot analysis. (G) Jurkat cells $(500,000$ cells/ml) were treated with vehicle ( $0.2 \%$ (v/v) ethanol) or PBOX-15 $(1 \mu \mathrm{M}) \pm$ wild-type TRAIL [TRAIL (WT)] or DR5-selective TRAIL variant D269H/E195R [TRAIL (DR5)] at concentrations of 20-100 ng/ml. (H) Jurkats were pre-treated for $1 \mathrm{~h}$ with neutralising monoclonal DR5 antibodies $(1 \mu \mathrm{g} / \mathrm{ml})$ followed by treatment with vehicle or PBOX-15 $(1 \mu \mathrm{M}) \pm 20 \mathrm{ng} / \mathrm{ml}$ TRAIL (WT) or TRAIL (DR5). (G and H) The cells were fixed in ethanol, stained with propidium iodide and their DNA content assessed by flow cytometry. Analysis of data was performed using the CellQuest software. Fluorescence was proportional to the amount of DNA present in each entity and therefore indicated the stage of the cell cycle. Cells in the $s_{b} G_{0} / G_{1}$ phase $(<2 \mathrm{~N}$ DNA) were deemed apoptotic. Values represent the mean \pm SEM. Graphs and blots are representative of three independent experiments.

caspase-8 (z-IETD-fmk), caspase-9 (z-LEHD-fmk) and a general broad-range caspase inhibitor (z-VAD-fmk). The broadrange inhibitor abrogated apoptosis induced by PBOX-15, TRAIL or the combination in both Jurkat and Nalm- 6 cells
(Fig. 6D). For example, the PBOX/TRAIL combination resulted in $38.7 \pm 4.9 \%$ apoptosis in Jurkats and $34.7 \pm 1.6 \%$ in Nalm-6 cells. Pre-treatment with z-VAD-fmk reduced TRAIL/PBOX-15-induced apoptosis to $2.8 \pm 0.7 \%$ (Jurkat) and 

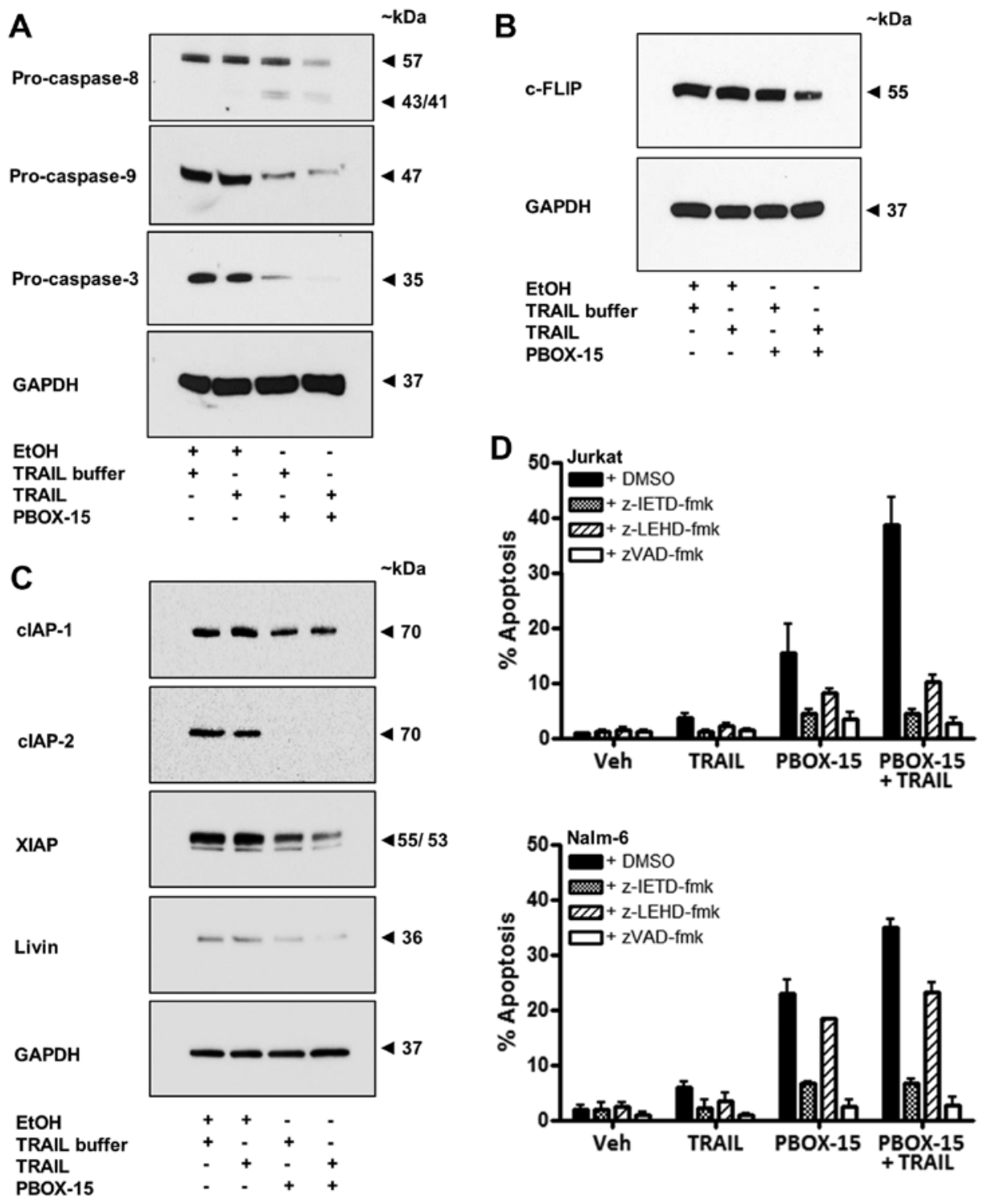

Figure 6. PBOX-15/TRAIL-induced apoptosis occurs in a caspase-dependent manner and is associated with reduced expression of c-FLIP and IAPs in Jurkat ALL cells. Jurkat cells $(500,000$ cells $/ \mathrm{ml})$ were treated with vehicle $[0.2 \%(\mathrm{v} / \mathrm{v})$ ethanol] or PBOX-15 $(1 \mu \mathrm{M}) \pm \mathrm{TRAIL}(20 \mathrm{ng} / \mathrm{ml})$ for $24 \mathrm{~h}$. Western blot analysis was then used to examine (A) cleavage of initiator pro-caspases-8 and -9 and effector pro-caspase-3, (B) expression of c-FLIP or (C) expression of IAPs (cIAP-1, cIAP-2, XIAP and livin). Levels of GAPDH were used as a loading control. Blots are representative of three independent experiments. (D) Jurkat or Nalm-6 cells $(500,000$ cells $/ \mathrm{ml})$ were pre-treated for $1 \mathrm{~h}$ with a solvent control [0.1\% (v/v) DMSO], a caspase-8 inhibitor (20 $\mu \mathrm{M} \mathrm{z-IETD-fmk),} \mathrm{a} \mathrm{caspase-9}$ inhibitor (20 $\mu \mathrm{M}$ z-LEHD-fmk) or a general caspase inhibitor (50 $\mu \mathrm{M} \mathrm{z}$-VAD-fmk). The cells were subsequently treated with vehicle $(0.2 \%$ (v/v) ethanol) or PBOX-15 $(1 \mu \mathrm{M}) \pm$ TRAIL $(20 \mathrm{ng} / \mathrm{ml})$ for $24 \mathrm{~h}$. The DNA content of cells fixed in ethanol and stained with propidium iodide was assessed by flow cytometry. Cells in the subG $G_{0} / G_{1}$ phase $\left(<2 \mathrm{~N}\right.$ DNA) were deemed apoptotic, while cells with $4 \mathrm{~N}$ quantities of DNA were considered to be in the $\mathrm{G}_{2} / \mathrm{M}$ phase of the cell cycle. Values represent the mean \pm SEM for three independent experiments.

$2.7 \pm 1.4 \%$ (Nalm-6), levels which are close to background apoptosis evident in control cells (Jurkat, $0.8 \pm 0.1 \%$ and Nalm-6, $1.9 \pm 0.7 \%$ ). These findings confirmed that PBOX/TRAILinduced apoptosis occurred in a caspase-dependent manner. The caspase- 8 inhibitor reduced PBOX/TRAIL-induced apoptosis to only $4.5 \pm 0.7 \%$ in Jurkat or $6.7 \pm 0.7 \%$ in Nalm-6 cells, illustrating the importance of caspase- 8 and the extrinsic pathway in the apoptotic response induced by PBOX-15 and TRAIL in ALL cells. In Jurkat cells, although not quite as effectively as the caspase- 8 inhibitor, the caspase- 9 inhibitor also resulted in a significant reduction in TRAIL/PBOX-15induced apoptosis $(10.2 \pm 1.3 \%)$, highlighting the importance of caspase- 9 and the intrinsic apoptotic pathway in Jurkat (type II) cells. Conversely, in Nalm-6 cells, the caspase-9 inhibitor only reduced TRAIL/PBOX-15-induced apoptosis to $23.1 \pm 1.9 \%$, indicating that signalling through the intrinsic pathway may not be as important in B cell precursor Nalm-6 cells as in Jurkat T cells.

Effect of PBOX-15 alone or in combination with TRAIL on mitochondrial membrane potential (MMP) and the Bcl-2 family in Jurkat ALL cells. We next determined whether exposure of Jurkats to PBOX-15 alone or in combination with TRAIL can alter MMP using the potentiometric dye JC-1. A decrease in the red:green fluorescent ratio of JC-1 stained cells as detected by flow cytometry is indicative of a loss in MMP and hence, mitochondrial depolarisation. Both PBOX-15 alone and in combination with TRAIL significantly increased the 
A
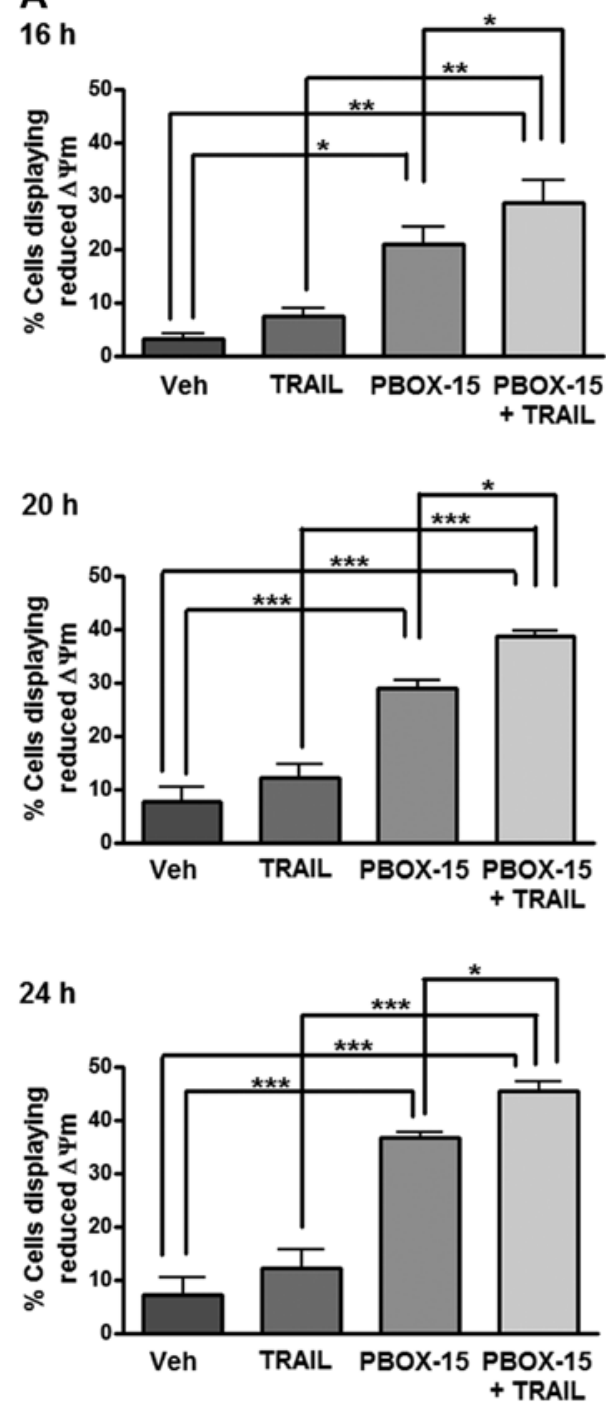

B

Bcl-2

$\beta$-tubulin

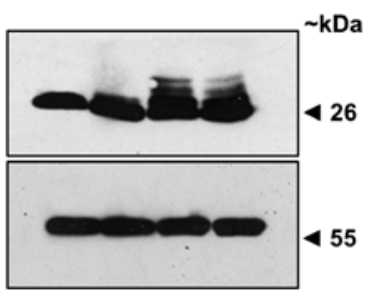

Bcl-xL

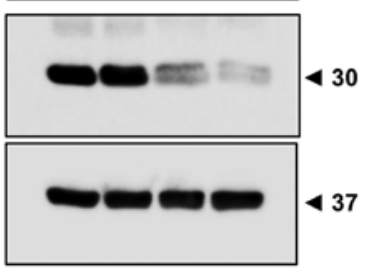

Mcl-1

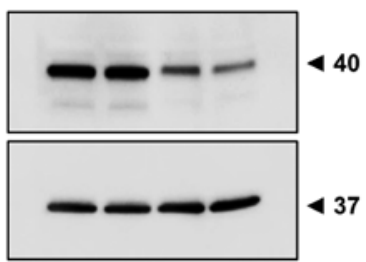

GAPDH

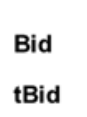

tBid

Bim $_{\text {EL }}$

$\operatorname{Bim}_{\mathrm{L}}$

$\mathrm{Bim}_{\mathrm{s}}$

GAPDH
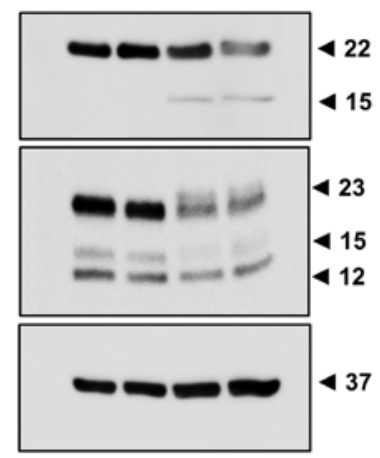

EtOH

TRAIL buffer

TRAIL

PBOX-15

Figure 7. PBOX-15/TRAIL-induced reduction in mitochondrial membrane potential $(\Delta \Psi \mathrm{m})$ is accompanied by phosphorylation and/or degradation of antiapoptotic proteins, Bcl-2, Bcl-xL and Mcl-1, and processing of pro-apoptotic BH3-only proteins, Bid and Bim, in Jurkat ALL cells. Jurkat cells (500,000 cells/ $\mathrm{ml})$ were treated with vehicle $[0.2 \%(\mathrm{v} / \mathrm{v})$ ethanol] or PBOX-15 $(1 \mu \mathrm{M}) \pm$ TRAIL $(20 \mathrm{ng} / \mathrm{ml})$. (A) Mitochondrial membrane potential was assessed 16,20 or $24 \mathrm{~h}$ post-treatment by incubation with JC-1 and analysis by flow cytometry. Values represent the mean \pm SEM for three independent experiments. A P-value of $<0.05$ was considered to be statically significant $\left({ }^{*} \mathrm{P}<0.05,{ }^{* *} \mathrm{P}<0.01,{ }^{* * *} \mathrm{P}<0.001\right)$. (B) Twenty-four hours post-treatment, western blotting was used to assess protein expression of anti-apoptotic proteins, Bcl-2, Bcl-xL and Mcl-1 or pro-apoptotic BH3-only proteins, Bid and Bim. Expression of $\beta$-tubulin or GAPDH was used as a loading control. Blots are representative of three independent experiments.

number of Jurkat cells with reduced MMP following treatment for 16, 20 or $24 \mathrm{~h}$ (Fig. 7A). For example, after 20-h treatment with PBOX-15, the number of cells exhibiting mitochondrial depolarisation was $21.0 \pm 3.3 \%$ compared to only $3.2 \pm 1.0 \%$ in the vehicle-treated cells $(\mathrm{P}<0.001)$. Furthermore, exposure to the combination resulted in a statistically significant increase in the number of cells displaying reduced MMP compared to either agent alone, such as after $20 \mathrm{~h}$ the combination resulted in $28.8 \pm 4.1 \%$ cells with membrane depolarisation compared to $21.0 \pm 3.3 \%$ with PBOX-15 alone $(\mathrm{P}<0.05)$. Collectively, these findings support a role for the involvement of the mitochondrial pathway during PBOX-TRAIL-induced apoptosis.

The Bcl-2 family of proteins are involved in the control of mitochondrial membrane potential and subsequent downstream signalling. Overexpression of anti-apoptotic Bcl-2 proteins can confer resistance of cells to inducers of apoptosis such as TRAIL. Therefore, the ability of a compound to overcome such resistance can be beneficial therapeutically. We assessed the effect of PBOX-15 and TRAIL on the antiapoptotic Bcl-2 family members, Bcl-2, Bcl-xL and Mcl-1 (Fig. 7B). Treatment of Jurkats for $24 \mathrm{~h}$ with PBOX-15 alone or in combination with TRAIL resulted in hyper-phosphorylation of Bcl-2 evidenced by slower migrating bands on a western blot analysis. Phosphorylation and degradation of Bcl-xL was also evident following either treatment, as was degradation of Mcl-1. These results suggest that PBOX-15 treatment may inactivate anti-apoptotic Bcl-2 proteins in ALL cells.

Pro-apoptotic Bid is activated by its proteolytic cleavage by caspase- 8 . Cleaved or truncated Bid (tBid) translocates to the mitochondria where it can induce cytochrome $c$ release. Western blotting indicated that treatment of Jurkat cells with PBOX-15 induced cleavage of inactive precursor Bid (22 kDa) and the appearance of a band corresponding to the cleaved tBid fragment (15 kDa) (Fig. 7B). This result further demonstrates 
A

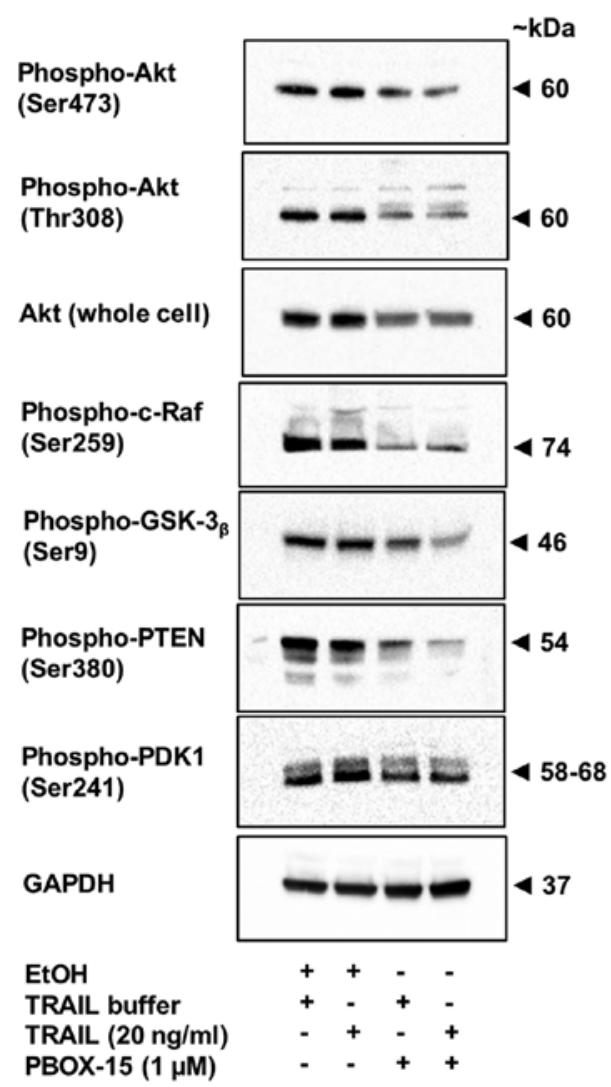

B
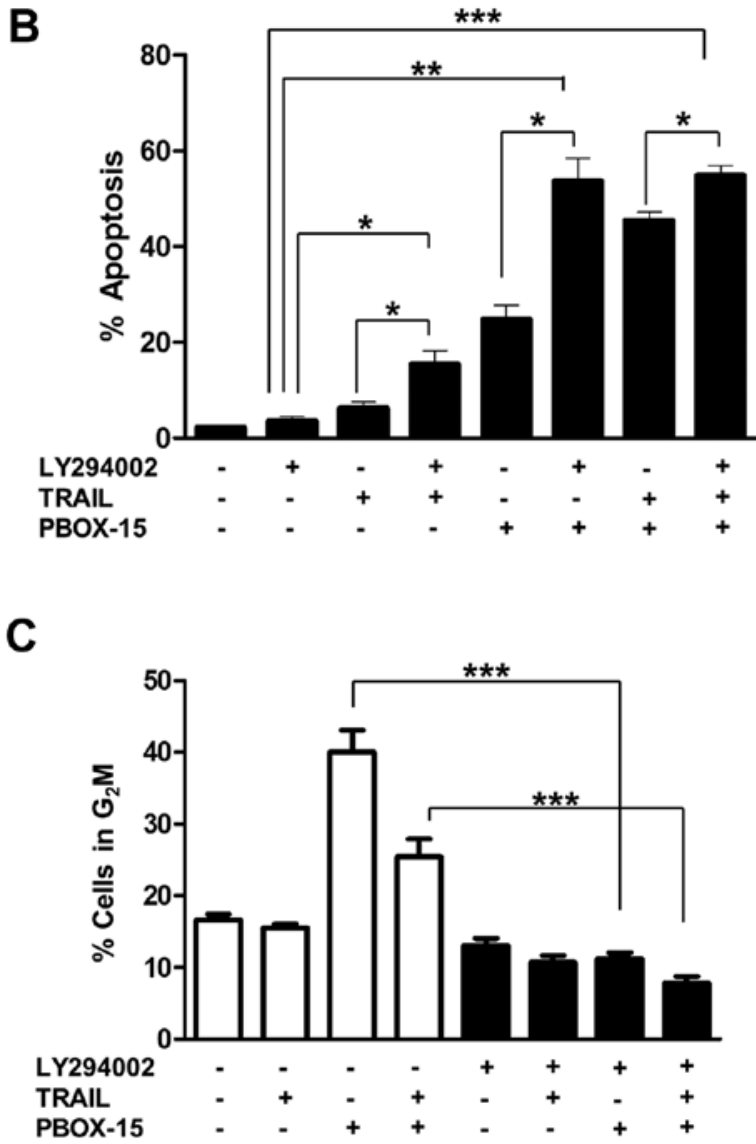

Figure 8. PBOX-15 in combination with TRAIL inhibits the Akt survival pathway and the PI3K inhibitor LY294002 significantly enhances the apoptotic potential of this combination. (A) Jurkat cells $(500,000$ cells $/ \mathrm{ml})$ were treated with vehicle $[0.2 \%$ (v/v) ethanol] or PBOX-15 (1 $\mu \mathrm{M}) \pm \mathrm{TRAIL}(20 \mathrm{ng} / \mathrm{ml})$ for $24 \mathrm{~h}$. Phosphorylation and expression of Akt pathway proteins and GAPDH (loading control) was assessed by western blot analysis. Blots are representative of three independent experiments. (B and C) Jurkat cells $(500,000 / \mathrm{ml})$ were pre-treated for $1 \mathrm{~h}$ with a solvent control $[0.1 \%(\mathrm{v} / \mathrm{v}) \mathrm{DMSO}] \mathrm{or} \mathrm{LY} 294002(10 \mu \mathrm{M})$. The cells were subsequently treated with vehicle $[0.1 \%(\mathrm{v} / \mathrm{v})$ ethanol] or PBOX-15 $(1 \mu \mathrm{M}) \pm$ TRAIL $(20 \mathrm{ng} / \mathrm{ml})$ for $24 \mathrm{~h}$. The cells were fixed in ethanol, stained with propidium iodide and their DNA content assessed by flow cytometry. Analysis of data was performed using the CellQuest software. Fluorescence was proportional to the amount of DNA present in each entity and therefore indicated the stage of the cell cycle. Cells in the sub $\mathrm{G}_{0} / \mathrm{G}_{1}$ phase $(<2 \mathrm{~N}$ DNA) were deemed apoptotic (B), while cells with a DNA content of $4 \mathrm{~N}$ are considered to be in the $\mathrm{G}_{2} \mathrm{M}$ phase $(\mathrm{C})$. Values represent the mean \pm SEM for 4 independent experiments $\left({ }^{*} \mathrm{P}<0.05,{ }^{* *} \mathrm{P}<0.01,{ }^{* * *} \mathrm{P}<0.001\right)$.

the involvement of crosstalk between extrinsic pathways and the intrinsic mitochondrial pathway in PBOX-15/TRAILinduced ALL cell apoptosis.

Three alternatively spliced isoforms of $\mathrm{BH} 3$-only protein Bim exist and are known as BimEL, BimL and BimS. Although Bim is a pro-apoptotic protein, decreased expression of BimEL has been postulated to result in a cleaved form of Bim that displays increased pro-apoptotic activity in Jurkats cells (35). Herein, we demonstrate that PBOX-15 alone or in combination with TRAIL resulted in decreased expression of BimEL and BimL (Fig. 7B).

Effect of PBOX-15 alone and in combination with TRAIL on the PI3K/Akt signalling pathway. The phosphoinositide 3-kinase (PI3K)/Akt pro-survival signal transduction pathway can confer an aggressive apoptosis-resistant phenotype to acute leukaemia cells (36). Jurkat ALL cells display high levels of Akt activation. Treatment of Jurkat cells with PBOX-15 alone and in combination with TRAIL lead to decreased expression of both phosphorylated (Ser473 and Thr308) and total cellular Akt (Fig. 8A). Expression of downstream targets of phosphoAkt, namely, phospho-c-Raf (Ser259) and phospho-GSK-3 $\beta$
(Ser9) and were also found to be decreased after treatment (Fig. 8A). Levels of phospho-PDK1 (ser241) were also slightly decreased (Fig. 8A). This molecule functions up-stream of Akt and is responsible for its phosphorylation at Thr308. Notably, expression of the inactive form of PTEN, Phospho-PTEN (Ser380), was also decreased (Fig. 8A). Dephosphorylated $\mathrm{PTEN}$ is a negative regulator of the Akt/PI3K pathway via dephosphorylation of $\mathrm{PIP}_{3}$ to $\mathrm{PIP}_{2}$. $\mathrm{PIP}_{3}$ is required for activation of PDK1 and thus Akt phosphorylation (37).

To understand the role of Akt inactivation in PBOX-15 and TRAIL-induced apoptosis, Jurkat cells were pretreated with the PI3K inhibitor LY294002 for $1 \mathrm{~h}$, followed by treatment with PBOX-15, TRAIL or both for $24 \mathrm{~h}$. Apoptosis was monitored by flow cytometric analysis of PI stained cells. As shown in Fig. 8B a non-toxic concentration of LY294002 $(10 \mu \mathrm{M})$ with a marginally toxic concentration of TRAIL $(20 \mathrm{ng} / \mathrm{ml}$ : $8 \%)$ or modestly active concentration of PBOX-15 $(1 \mu \mathrm{M}$ : $\sim 25 \%$ ) at least doubled the amount of apoptosis. Inhibition of the PI3K/Akt pathway also significantly increased the amount of apoptosis when both PBOX-15 and TRAIL were combined. This enhancement of apoptosis was associated with an inhibition of PBOX-15-induced $\mathrm{G}_{2} \mathrm{M}$ arrest (Fig. 8C). Taken together 
with the Akt western blot experiments, these findings suggest that inactivation of Akt plays a central role in both PBOX-15 and TRAIL-induced apoptosis in ALL cells.

\section{Discussion}

TRAIL is an established tumour targeting agent able to selectively eradicate cancer cells by activating a signalling pathway adapted by the innate immune system (38). However, the therapeutic potential of TRAIL is limited by resistance mechanisms. Furthermore, recent studies demonstrated TRAIL-dependent tumour promoting activities (13). Combination therapies can frequently amplify the actions of anticancer agents and widen the therapeutic window. Extensive research into the survival pathways mediating cellular resistance to TRAIL has identified several targets for strategic combinational therapies. In this study, we investigated the therapeutic potential in combining TRAIL with another tumour selective agent, PBOX-15 in overcoming common mediators of TRAIL resistance.

The preliminary determinant of TRAIL-sensitivity is the expression levels of TRAIL receptors on tumor cells. Low expression of agonist DR4 and DR5 receptors has been shown to limit TRAIL-induced apoptosis in many cancers including ALL (39-42). Mutations within the ligand binding or death domain of agonist TRAIL receptors can also impede the apoptotic potential of TRAIL $(41,43)$. Furthermore, nuclear localization of DR5 mediated by importin- $\beta 1$ can significantly reduce TRAIL-mediated cell death in cancer cells (44). It is postulated that high expression of decoy antagonistic receptors on tumour cell surfaces may compete with agonistic receptors and reduce the overall apoptotic potential of TRAIL (45). TRAIL resistance mediated by agonist receptor expression levels can be overcome by combining TRAIL with agents that induce the expression of DR4 and DR5 on tumour cells. The chemotherapeutics etoposide, doxorubicin and paclitaxel $(32,46,47)$, the antitumour antibiotic Bleomycin $(48)$, and the histone deacetylase inhibitor MS-275 (49) have been shown amongst others to upregulate DR4 and DR5 and thus sensitise various cancer cells to TRAIL-induced apoptosis. Similarly, our group demonstrated that novel mictotubulin-targeting agent PBOX-15 synergistically enhanced TRAIL-induced apoptosis in myeloma cells via upregulation of DR5 (17). Herein, we report that PBOX-15 synergistically enhanced the apoptotic potential of TRAIL in T-cell and B-cell precursor ALL-derived cell lines. PBOX-15 enhanced DR5-selective variant-induced apoptosis in Jurkat ALL cells with the same magnitude as wild-type and upregulated the expression of DR5. Binding of TRAIL to DR4/5 leads to assembly of the death inducing signaling complex (DISC). Caspase- 8 is recruited to DISC where it is activated and triggers apoptosis via the extrinsic pathway. In the present study, we demonstrate that caspase- 8 is activated during PBOX-15/TRAIL apoptotic synergy in ALL cells. Furthermore, the specific caspase- 8 inhibitor (z-IETD-fmk) significantly inhibited apoptosis. These findings support a role for caspase- 8 in PBOX-15mediated enhancement of TRAIL-induced apoptosis in ALL and complement previous findings demonstrating caspase8-dependent PBOX-15/TRAIL apoptotic synergy in multiple myeloma cells. Taken together, these findings suggest that PBOX-15 co-operates with TRAIL by upregulation of DR5 in cancer cells promoting TRAIL-induced apoptosis via the extrinsic pathway.

Activation of the intrinsic apoptotic pathway was also evident by activation of caspase-9, MIM depolarisation and Bid cleavage in response to PBOX-15/TRAIL combinations. Given that the specific caspase-9 inhibitor (z-LEHD-fmk) only partially inhibited PBOX-15 alone and PBOX-15/TRAILinduced apoptosis it may be inferred that the extrinsic apoptotic pathway is dominant in ALL cells in response to these agents. There is also the possibility of cross-talk between the extrinsic and intrinsic pathways initiated by PBOX-15 alone and when combined with TRAIL. Caspase- 8 has been shown to cleave Bid with subsequent translocation of truncated Bid to the mitochondria where it interacts with Bax and Bak promoting cytochrome $c$ release (50). This cascade of events was recently demonstrated following death receptor activation by TRAIL linking both intrinsic and extrinsic apoptotic pathways (51). We hypothesise that following exposure to PBOX-15/TRAIL the extrinsic pathway is activated which in turn activates caspase- 8 which then cleaves Bid thus activating the intrinsic pathway and amplifying the initial apoptotic signal following death receptor activation.

Several studies have demonstrated some critical cell survival proteins such as cellular FLICE (FADD-like IL-1 $\beta$ converting enzyme)-inhibitory protein (c-FLIP), members of the Bcl-2 family of anti-apoptotic proteins and inhibitor of apoptosis proteins (IAPs) in TRAIL resistance. In more detail, c-FLIP is an anti-apoptotic regulator that inhibits TRAILinduced apoptosis in malignant cells (52), and c-FLIP binds to FADD and/or caspase- 8 or -10 and DR5 preventing DISC formation and subsequent activation of the caspase cascade (53). High expression of c-FLIP correlates with TRAIL resistance in cancer cells $(49,54)$, and c-FLIP-mediated TRAIL resistance can be overcome by combining with c-FLIP targeting chemotherapeutics $(55,56)$ or c-FLIP siRNA $(57)$. In the present study, we demonstrate for the first time that PBOX-15 can downregulate c-FLIP, resulting in increased TRAIL-induced apoptosis in ALL cells.

The anti-apoptotic protein Mcl-1 is a member of the Bcl-2 family and plays an important role in the survival of malignant hematopoietic cells (58). Several pharmacological strategies targeting the anti-apoptotic proteins Bcl-2 or Bcl-xL are currently undergoing clinical trials for the treatment of hematological malignancies (59). We recently demonstrated that the PBOXs can induce both Bcl-2-dependent (60) and -independent (20) apoptosis in leukaemia cells. The PBOXs also phosphorylate and inactive Bcl-xL $(29,60)$. The effects of the PBOXs on the Bcl-2 family of anti-apoptotic proteins were amplified when combined with established chemotherapeutics such as imatinib mesylate (21), carboplatin (61) or the autophagy inhibitor bafilomycin-a1 (62). In this study, we demonstrate that PBOX-15 induces the phosphorylation and inactivation of Bcl-2 and Bcl-xL and also led to a decrease in Mcl-1 protein levels. Taken together, these results demonstrate the potential therapeutic efficacy of the PBOX's in targeting the anti-apoptotic members of the Bcl-2 family and sensitising cancer cells to various chemotherapeutics and cytokines.

We also report novel findings demonstrating downregulation of XIAP, cIAP-1 and cIAP-2 in the PBOX-15-induced 
apoptotic pathway. Expression of XIAP and cIAP-2 is associated with resistance to TRAIL in prostate cancer cells (63). Genetic knockdown of IAP expression restored TRAIL sensitivity in these cells. Similarly, small molecule IAP antagonists were shown to sensitise various cancer cells to TRAIL-induced apoptosis (64). Several studies suggest therapeutic benefit in combining agents targeting IAP expression in combination with TRAIL (65). Importantly, small molecule XIAP inhibitors were shown to co-operate with TRAIL to induce apoptosis in pediatric ALL (14). Accordingly, the levels of XIAP decreased further when PBOX-15 combined with TRAIL in ALL cells confirming that agents targeting XIAP can co-operate with TRAIL to induce apoptosis in ALL. This finding supports other independent results demonstrating a requirement for cIAP-1 and cIAP-2 downregulation in the signalling pathway mediating TRAIL/Tyrphostin (a selective Janus kinase 2 inhibitor) apoptotic synergy in ALL cells (66).

Our data also demonstrate for the first time that PBOX-15 reduces the levels of whole cell and phosphorylated Akt suggesting that reduction of Akt may facilitate PBOX-induced apoptosis. Akt is a serine/threonine kinase and a target of phosphatidylinositol 3-kinase/PI3K. Akt plays a pivotal role in proliferation and survival and is frequently altered in human cancers (67). PBOX-15/TRAIL combination also showed decreased Akt expression and consequently a decrease in the phosphorylation status of downstream targets c-Raf and GSK- $3_{\beta}$. Adult ALL cells display constitutive hyperactivation of the PI3K/Akt pathway highlighting this system as a novel therapeutic target for the treatment of ALL (68). Subsequent studies with the PI3K inhibitor LY294002 demonstrated increased sensitivity to TRAIL and PBOX-15 alone and in combination suggesting inhibition of the PI3K/Akt signalling sensitises ALL cells to apoptotic effects of TRAIL and PBOX-15. These findings support recent results demonstrating therapeutic benefits by inhibition of the PI3K/Akt/mTOR pathway in patients with ALL (69).

In conclusion, we demonstrate that PBOX-15-mediated sensitisation of ALL cells to TRAIL-induced apoptosis can be attributed to activation of the extrinsic apoptotic pathway, cross activation of the intrinsic apoptotic pathway and targeting several key cell survival pathways. As similar events have been reported with other MTAs it seems likely that microtubular destabilisation by PBOX-15 plays an important role in the mechanism underlying these effects. Further characterisation of the mechanism of PBOX-15-induced upregulation of DR5 and downregulation of survival pathways would allow the strategic development of improved treatment regimens for PBOX-15/TRAIL combinations. We provide preliminary data to support the combination of TRAIL/PBOX-15 with the PI3K inhibitor LY294002 to further enhance apoptotic outcomes in pediatric ALL. Results presented herein will contribute to identifying optimum use of this cytokine in the clinic.

\section{Acknowledgements}

The funding for the present study was provided by The Children's Leukaemia Research Project, Ireland. We acknowledge the assistance of the technical staff of the School of Biochemistry and Immunology, Biomedical Sciences Institute,
Trinity College Dublin, Ireland, in particular, Mr. Barry Moran of the Flow Cytometry Facility.

\section{References}

1. Inaba H, Greaves $M$ and Mullighan CG: Acute lymphoblastic leukaemia. Lancet 381: 1943-1955, 2013.

2. Banihashem A, Ghasemi A, Ghaemi N, Moazzen N and Amirabadi A: Prevalence of transient hyperglycemia and diabetes mellitus in pediatric patients with acute leukemia. Iran J Ped Hematol Oncol 4: 5-10, 2014.

3. Woo JS, Alberti MO and Tirado CA: Childhood B-acute lymphoblastic leukemia: A genetic update. Exp Hematol Oncol 3: 16,2014

4. Guicciardi ME and Gores GJ: Life and death by death receptors. FASEB J 23: 1625-1637, 2009.

5. French LE and Tschopp J: Protein-based therapeutic approaches targeting death receptors. Cell Death Differ 10: 117-123, 2003.

6. Prasad S, Kim JH, Gupta SC and Aggarwal BB: Targeting death receptors for TRAIL by agents designed by Mother Nature. Trends Pharmacol Sci 35: 520-536, 2014.

7. Daniels RA, Turley H, Kimberley FC, Liu XS, Mongkolsapaya J, Ch'En P, Xu XN, Jin BQ, Pezzella F and Screaton GR: Expression of TRAIL and TRAIL receptors in normal and malignant tissues. Cell Res 15: 430-438, 2005.

8. Wang S and El-Deiry WS: TRAIL and apoptosis induction by TNF-family death receptors. Oncogene 22: 8628-8633, 2003.

9. Stuckey DW and Shah K: TRAIL on trial: Preclinical advances in cancer therapy. Trends Mol Med 19: 685-694, 2013.

10. Bellail AC, Qi L, Mulligan P, Chhabra V and Hao C: TRAIL agonists on clinical trials for cancer therapy: The promises and the challenges. Rev Recent Clin Trials 4: 34-41, 2009.

11. Mahalingam D, Szegezdi E, Keane M, de Jong S and Samali A: TRAIL receptor signalling and modulation: Are we on the right TRAIL? Cancer Treat Rev 35: 280-288, 2009.

12. Ashkenazi A, Holland P and Eckhardt SG: Ligand-based targeting of apoptosis in cancer: The potential of recombinant human apoptosis ligand 2/Tumor necrosis factor-related apoptosis-inducing ligand (rhApo2L/TRAIL). J Clin Oncol 26: 3621-3630, 2008.

13. Ehrhardt H, Fulda S, Schmid I, Hiscott J, Debatin KM and Jeremias I: TRAIL induced survival and proliferation in cancer cells resistant towards TRAIL-induced apoptosis mediated by NF-kappaB. Oncogene 22: 3842-3852, 2003.

14. Fakler M, Loeder S, Vogler M, Schneider K, Jeremias I, Debatin KM and Fulda S: Small molecule XIAP inhibitors cooperate with TRAIL to induce apoptosis in childhood acute leukemia cells and overcome Bcl-2-mediated resistance. Blood 113: 1710-1722, 2009.

15. Hellwig CT and Rehm M: TRAIL signaling and synergy mechanisms used in TRAIL-based combination therapies. Mol Cancer Ther 11: 3-13, 2012.

16. Leong S, Cohen RB, Gustafson DL, Langer CJ, Camidge DR, Padavic K, Gore L, Smith M, Chow LQ, von Mehren M, et al: Mapatumumab, an antibody targeting TRAIL-R1, in combination with paclitaxel and carboplatin in patients with advanced solid malignancies: Results of a phase I and pharmacokinetic study. J Clin Oncol 27: 4413-4421, 2009.

17. Maginn EN, Browne PV, Hayden P, Vandenberghe E, MacDonagh B, Evans P, Goodyer M, Tewari P, Campiani G, Butini S, et al: PBOX-15, a novel microtubule targeting agent, induces apoptosis, upregulates death receptors, and potentiates TRAIL-mediated apoptosis in multiple myeloma cells. Br J Cancer 104: 281-289, 2011.

18. Mulligan JM, Greene LM, Cloonan S, Mc Gee MM, Onnis V, Campiani G, Fattorusso C, Lawler M, Williams DC and Zisterer DM: Identification of tubulin as the molecular target of proapoptotic pyrrolo-1,5-benzoxazepines. Mol Pharmacol 70: 60-70, 2006.

19. Lysaght J, Verma NK, Maginn EN, Ryan JM, Campiani G, Zisterer DM, Williams DC, Browne PV, Lawler MP and McElligott AM: The microtubule targeting agent PBOX-15 inhibits integrin-mediated cell adhesion and induces apoptosis in acute lymphoblastic leukaemia cells. Int J Oncol 42: 239-246, 2013. 
20. McElligott AM, Maginn EN, Greene LM, McGuckin S, Hayat A, Browne PV, Butini S, Campiani G, Catherwood MA, Vandenberghe $\mathrm{E}$, et al: The novel tubulin-targeting agent pyrrolo-1,5-benzoxazepine-15 induces apoptosis in poor prognostic subgroups of chronic lymphocytic leukemia. Cancer Res 69: 8366-8375, 2009.

21. Greene LM, Kelly L, Onnis V, Campiani G, Lawler M, Williams DC and Zisterer DM: STI-571 (imatinib mesylate) enhances the apoptotic efficacy of pyrrolo-1,5-benzoxazepine-6, a novel microtubule-targeting agent, in both STI-571-sensitive and -resistant Bcr-Abl-positive human chronic myeloid leukemia cells. J Pharmacol Exp Ther 321: 288-297, 2007.

22. Zisterer DM, McGee MM, Campiani G, Ramunno A, Fattorusso C, Nacci V, Lawler M and Williams DC: Pyrrolo-1,5benzoxazepines: A new class of apoptotic agents. Biochem Soc Trans 29: 704-706, 2001.

23. Nathwani SM, Butler S, Fayne D, McGovern NN, Sarkadi B, Meegan MJ, Lloyd DG, Campiani G, Lawler M, Williams DC, et al: Novel microtubule-targeting agents, pyrrolo-1,5-benzoxazepines, induce apoptosis in multi-drug-resistant cancer cells Cancer Chemother Pharmacol 66: 585-596, 2010.

24. Bright SA, McElligott AM, O'Connell JW, O'Connor L, Carroll P, Campiani G, Deininger MW, Conneally E, Lawler M, Williams DC, et al: Novel pyrrolo-1,5-benzoxazepine compounds display significant activity against resistant chronic myeloid leukaemia cells in vitro, in ex vivo patient samples and in vivo. Br J Cancer 102: 1474-1482, 2010.

25. Mc Gee MM, Gemma S, Butini S, Ramunno A, Zisterer DM, Fattorusso C, Catalanotti B, Kukreja G, Fiorini I, Pisano C, et al: Pyrrolo[1,5]benzoxa(thia)zepines as a new class of potent apoptotic agents. Biological studies and identification of an intracellular location of their drug target. J Med Chem 48: 4367-4377, 2005.

26. van der Sloot AM, Mullally MM, Fernandez-Ballester G, Serrano L and Quax WJ: Stabilization of TRAIL, an all-betasheet multimeric protein, using computational redesign. Protein Eng Des Sel 17: 673-680, 2004.

27. van der Sloot AM, Tur V, Szegezdi E, Mullally MM, Cool RH, Samali A, Serrano L and Quax WJ: Designed tumor necrosis factor-related apoptosis-inducing ligand variants initiating apoptosis exclusively via the DR5 receptor. Proc Natl Acad Sci USA 103: 8634-8639, 2006.

28. Greene LM, Campiani G, Lawler M, Williams DC and Zisterer DM: BubR1 is required for a sustained mitotic spindle checkpoint arrest in human cancer cells treated with tubulintargeting pyrrolo-1,5-benzoxazepines. Mol Pharmacol 73 . 419-430, 2008

29. Nathwani SM, Cloonan SM, Stronach M, Campiani G, Lawler M, Williams DC and Zisterer DM: Novel microtubule-targeting agents, pyrrolo-1,5-benzoxazepines, induce cell cycle arrest and apoptosis in prostate cancer cells. Oncol Rep 24: 1499-1507, 2010.

30. Sung B, Park B, Yadav VR and Aggarwal BB: Celastrol, a triterpene, enhances TRAIL-induced apoptosis through the down-regulation of cell survival proteins and up-regulation of death receptors. J Biol Chem 285: 11498-11507, 2010.

31. Nimmanapalli R, Perkins CL, Orlando M, O'Bryan E, Nguyen D and Bhalla KN: Pretreatment with paclitaxel enhances apo-2 ligand/tumor necrosis factor-related apoptosis-inducing ligandinduced apoptosis of prostate cancer cells by inducing death receptors 4 and 5 protein levels. Cancer Res 61: 759-763, 2001.

32. Hunter TB, Manimala NJ, Luddy KA, Catlin T and Antonia SJ Paclitaxel and TRAIL synergize to kill paclitaxel-resistant small cell lung cancer cells through a caspase-independent mechanism mediated through AIF. Anticancer Res 31: 3193-3204, 2011.

33. Irmler $M$, Thome $M$, Hahne $M$, Schneider $P$, Hofmann $K$, Steiner V, Bodmer JL, Schröter M, Burns K, Mattmann C, et al: Inhibition of death receptor signals by cellular FLIP. Nature 388: 190-195, 1997.

34. Fulda S: Inhibitor of apoptosis (IAP) proteins in hematological malignancies: Molecular mechanisms and therapeutic opportunities. Leukemia 28: 1414-1422, 2014.

35. Chen D and Zhou Q: Caspase cleavage of BimEL triggers a positive feedback amplification of apoptotic signaling. Proc Nat Acad Sci USA 101: 1235-1240, 2004.

36. Tabellini G, Tazzari PL, Bortul R, Evangelisti C, Billi AM, Grafone T, Martinelli G, Baccarani M and Martelli AM: Phosphoinositide 3-kinase/Akt inhibition increases arsenic trioxide-induced apoptosis of acute promyelocytic and T-cell leukaemias. Br J Haematol 130: 716-725, 2005.
37. Franke TF: PI3K/Akt: Getting it right matters. Oncogene 27 6473-6488, 2008.

38. Mérino D, Lalaoui N, Morizot A, Solary E and Micheau O TRAIL in cancer therapy: Present and future challenges. Expert Opin Ther Targets 11: 1299-1314, 2007.

39. Akahane K, Inukai T, Zhang X, Hirose K, Kuroda I, Goi K, Honna H, Kagami K, Nakazawa S, Endo K, et al: Resistance of T-cell acute lymphoblastic leukemia to tumor necrosis factor-related apoptosis-inducing ligand-mediated apoptosis. Exp Hematol 38: 885-895, 2010

40. Zheng T, Fu JJ, Hu L, Qiu F, Hu M, Zhu JJ, Hua ZC and Wang H: Nanoarchitectured electrochemical cytosensors for selective detection of leukemia cells and quantitative evaluation of death receptor expression on cell surfaces. Anal Chem 85: 5609-5616, 2013.

41. Kim K, Fisher MJ, Xu SQ and el-Deiry WS: Molecular determinants of response to TRAIL in killing of normal and cancer cells. Clin Cancer Res 6: 335-346, 2000.

42. Zhang Y and Zhang B: TRAIL resistance of breast cancer cells is associated with constitutive endocytosis of death receptors 4 and 5. Mol Cancer Res 6: 1861-1871, 2008.

43. McDonald ER III, Chui PC, Martelli PF, Dicker DT and El-Deiry WS: Death domain mutagenesis of KILLER/DR5 reveals residues critical for apoptotic signaling. J Biol Chem 276: 14939-14945, 2001.

44. Kojima Y, Nakayama M, Nishina T, Nakano H, Koyanagi M, Takeda K, Okumura K and Yagita H: Importin $\beta 1$ protein-mediated nuclear localization of death receptor 5 (DR5) limits DR5/ tumor necrosis factor (TNF)-related apoptosis-inducing ligand (TRAIL)-induced cell death of human tumor cells. J Biol Chem 286: 43383-43393, 2011

45. Sheridan JP, Marsters SA, Pitti RM, Gurney A, Skubatch M, Baldwin D, Ramakrishnan L, Gray CL, Baker K, Wood WI, et al: Control of TRAIL-induced apoptosis by a family of signaling and decoy receptors. Science 277: 818-821, 1997.

46. Tong HX, Lu CW, Wang QS and Ma LY: Combination of IFN $\gamma$ and chemotherapeutic agents increase TRAIL sensitivity of neuroblastoma cell lines. Eur J Pediatr Surg 21: 304-309, 2011.

47. Kim HR, Lee MW, Kim DS, Jo HY, Lee SH, Chueh HW, Jung HL, Yoo KH, Sung KW and Koo HH: Etoposide sensitizes neuroblastoma cells expressing caspase 8 to TRAIL. Cell Biol Int Rep 2010 19: e00017, 2012.

48. Timur M, Cort A, Ozdemir E, Sarikcioglu SB, Sanlioglu S, Sanlioglu AD and Ozben T: Bleomycin induced sensitivity to TRAIL/Apo-2L-mediated apoptosis in human seminomatous testicular cancer cells is correlated with upregulation of death receptors. Anticancer Agents Med Chem 15: 99-106, 2015.

49. Venza I, Visalli M, Oteri R, Teti D and Venza M: Class I-specific histone deacetylase inhibitor MS-275 overrides TRAILresistance in melanoma cells by downregulating c-FLIP. Int Immunopharmacol 21: 439-446, 2014.

50. Green DR: Apoptotic pathways: Paper wraps stone blunts scissors. Cell 102: 1-4, 2000.

51. Schug ZT, Gonzalvez F, Houtkooper RH, Vaz FM and Gottlieb E: BID is cleaved by caspase- 8 within a native complex on the mitochondrial membrane. Cell Death Differ 18: 538-548, 2011.

52. Safa AR: c-FLIP, a master anti-apoptotic regulator. Exp Oncol 34: 176-184, 2012 .

53. Safa AR: Roles of c-FLIP in apoptosis, necroptosis, and autophagy. J Carcinog Mutagen (Suppl) 6: 003, 2013.

54. Zang F, Wei X, Leng X, Yu M and Sun B: C-FLIP(L) contributes to TRAIL resistance in HER2-positive breast cancer. Biochem Biophys Res Commun 450: 267-273, 2014.

55. Ding L, Yuan C, Wei F, Wang G, Zhang J, Bellail AC, Zhang Z, Olson JJ and Hao C: Cisplatin restores TRAIL apoptotic pathway in glioblastoma-derived stem cells through up-regulation of DR5 and down-regulation of c-FLIP. Cancer Invest 29: 511-520, 2011.

56. Ding J, Polier G, Köhler R, Giaisi M, Krammer PH and Li-Weber M: Wogonin and related natural flavones overcome tumor necrosis factor-related apoptosis-inducing ligand (TRAIL) protein resistance of tumors by down-regulation of c-FLIP protein and up-regulation of TRAIL receptor 2 expression. J Biol Chem 287: 641-649, 2012.

57. Li LC, Jayaram S, Ganesh L, Qian L, Rotmensch J, Maker AV and Prabhakar BS: Knockdown of MADD and c-FLIP overcomes resistance to TRAIL-induced apoptosis in ovarian cancer cells. Am J Obstet Gynecol 205: 362.e12-362.e25, 2011.

58. Bose P and Grant S: Mcl-1 as a therapeutic target in acute myelogenous leukemia (AML). Leuk Res Rep 2: 12-14, 2013. 
59. Scarfò L and Ghia P: Reprogramming cell death: BCL2 family inhibition in hematological malignancies. Immunol Lett 155: 36-39, 2013.

60. McGee MM, Greene LM, Ledwidge S, Campiani G, Nacci V, Lawler M, Williams DC and Zisterer DM: Selective induction of apoptosis by the pyrrolo-1,5-benzoxazepine 7-[[dimethylcarbamoyl]oxy]-6-(2-naphthyl)pyrrolo-[2,1-d] (1,5)-benzoxazepine (PBOX-6) in Leukemia cells occurs via the c-Jun NH2-terminal kinase-dependent phosphorylation and inactivation of Bcl-2 and Bcl-XL. J Pharmacol Exp Ther 310: 1084-1095, 2004.

61. Lennon JC, Bright SA, Carroll E, Butini S, Campiani G, O'Meara A, Williams DC and Zisterer DM: The novel pyrrolo1,5-benzoxazepine, PBOX-6, synergistically enhances the apoptotic effects of carboplatin in drug sensitive and multidrug resistant neuroblastoma cells. Biochem Pharmacol 87: 611-624, 2014.

62. Greene LM, Nolan DP, Regan-Komito D, Campiani G, Williams DC and Zisterer DM: Inhibition of late-stage autophagy synergistically enhances pyrrolo-1,5-benzoxazepine-6-induced apoptotic cell death in human colon cancer cells. Int J Oncol 43 . 927-935, 2013

63. Gill C, Dowling C, O'Neill AJ and Watson RW: Effects of cIAP-1, cIAP-2 and XIAP triple knockdown on prostate cancer cell susceptibility to apoptosis, cell survival and proliferation. Mol Cancer 8: 39, 2009.

64. Finlay D, Vamos M, González-López M, Ardecky RJ, Ganji SR, Yuan H, Su Y, Cooley TR, Hauser CT, Welsh K, et al: Small-molecule IAP antagonists sensitize cancer cells to TRAIL-induced apoptosis: Roles of XIAP and cIAPs. Mol Cancer Ther 13: 5-15, 2014.
65. Guicciardi ME, Mott JL, Bronk SF, Kurita S, Fingas CD and Gores GJ: Cellular inhibitor of apoptosis 1 (cIAP-1) degradation by caspase 8 during TNF-related apoptosis-inducing ligand (TRAIL)-induced apoptosis. Exp Cell Res 317: 107-116, 2011.

66. Lanuti P, Bertagnolo V, Pierdomenico L, Bascelli A, Santavenere E, Alinari L, Capitani S, Miscia S and Marchisio M: Enhancement of TRAIL cytotoxicity by AG-490 in human ALL cells is characterized by downregulation of cIAP-1 and cIAP-2 through inhibition of Jak2/Stat3. Cell Res 19: 1079-1089, 2009.

67. Osaki M, Oshimura $M$ and Ito H: PI3K-Akt pathway: Its functions and alterations in human cancer. Apoptosis 9: 667-676, 2004.

68. Gomes AM, Soares MV, Ribeiro P, Caldas J, Póvoa V, Martins LR, Melão A, Serra-Caetano A, de Sousa AB, Lacerda JF, et al: Adult B-cell acute lymphoblastic leukemia cells display decreased PTEN activity and constitutive hyperactivation of PI3K/Akt pathway despite high PTEN protein levels. Haematologica 99: 1062-1068, 2014

69. Badura S, Tesanovic T, Pfeifer H, Wystub S, Nijmeijer BA, Liebermann M, Falkenburg JH, Ruthardt $\mathrm{M}$ and Ottmann OG: Differential effects of selective inhibitors targeting the PI3K/ AKT/mTOR pathway in acute lymphoblastic leukemia. PLoS One 8: e80070, 2013. 